Materials Science and Engineering Laboratory

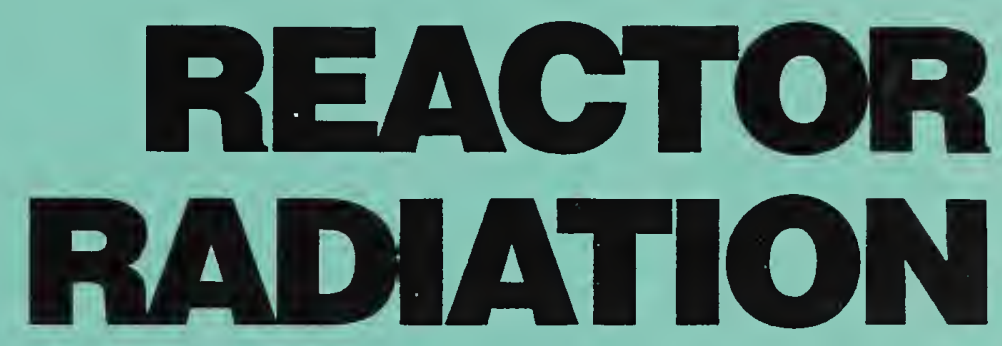

NAS-NRC

Assessment Panel

January 31-February 1, 1991

NISTIR 4398

U.S. Department of Commerce National Institute of Standards and Technology

\title{
NLT
}

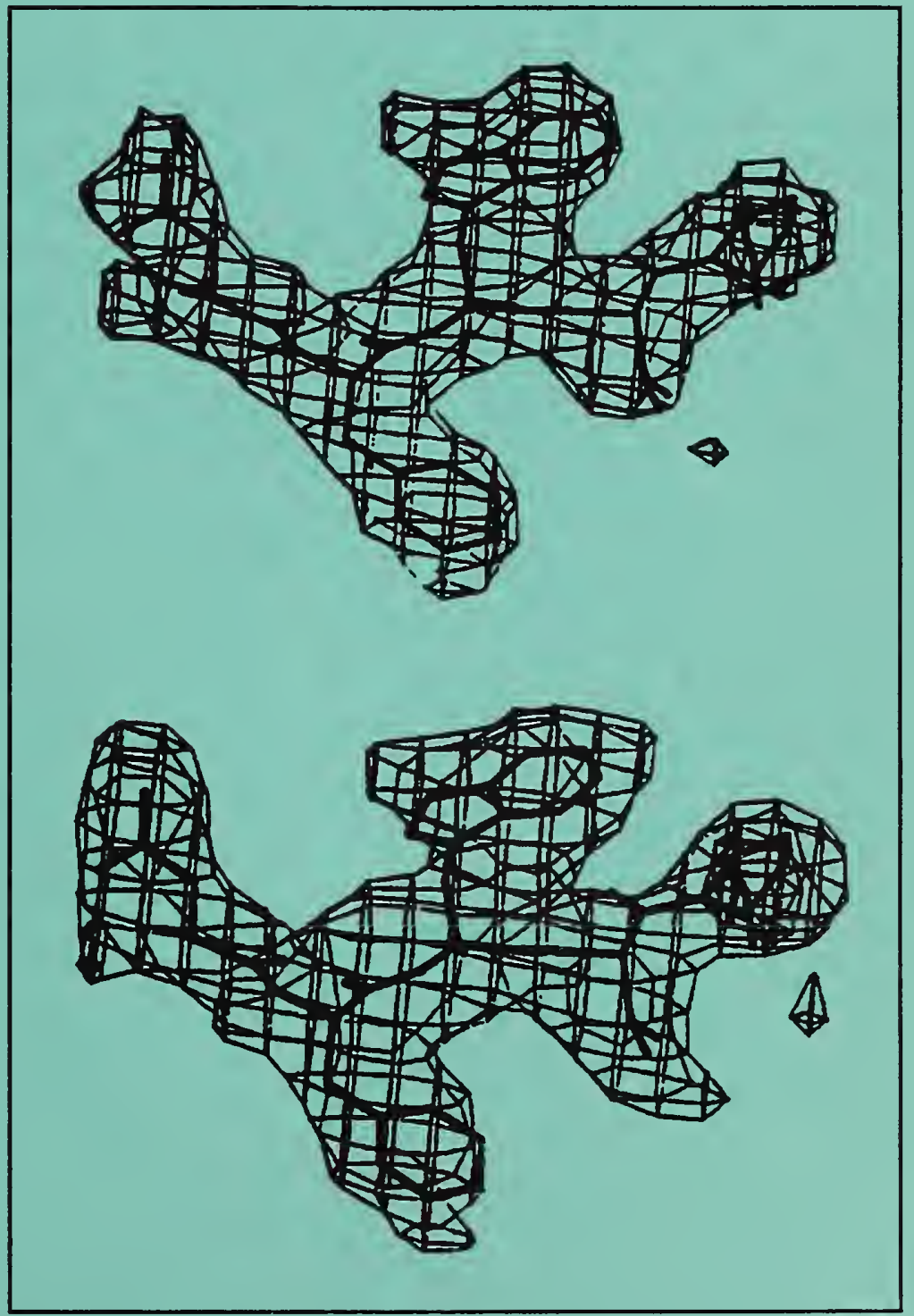

Technical Activities 1990 



\section{Materials Science and Engineering Laboratory}

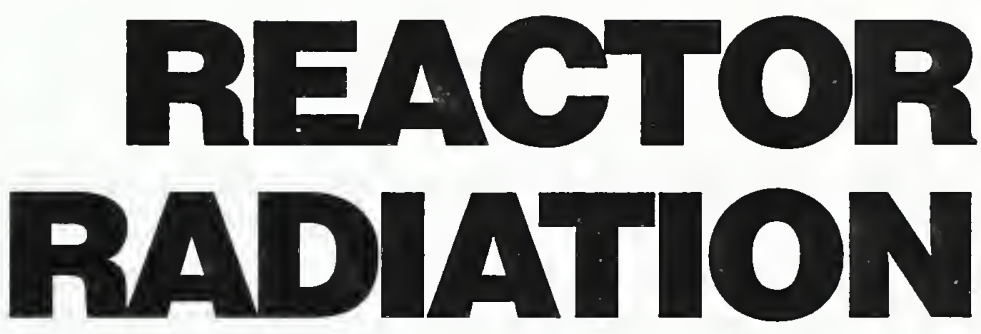

J.M. Rowe, Chief

T.M. Raby, Deputy

NAS-NRC

Assessment Panel

January 31-February 1, 1991

NISTIR 4398

U.S. Department of Commerce

National Institute of Standards

and Technology

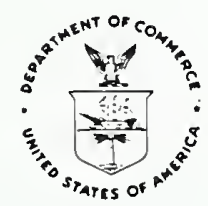

Technical Activities
1990 


\begin{abstract}
This report summarizes all those programs which depend on the NIST reactor. It covers the period from October 1, 1989 through September 30, 1990. The programs include the application of neutron methods to the characterization of materials, neutron standards, trace analysis by neutron activation analysis, neutron depth profiling, nondestructive evaluation, and the production of radioisotopes.
\end{abstract}

Key words: $\quad$ activation analysis; crystal structure; diffraction; isotopes; molecular dynamics; neutron; neutron radiography; nondestructive evaluation; nuclear reactor; radiation.

\title{
DISCLAIMER
}

Certain trade names and company products are identified to adequately specify the experimental procedure. In no case does such identification imply recommendation or endorsement by the National Institute of Standards and Technology, nor does it imply that the products are necessarily the best available for the purpose. 


\section{CONTENTS}

Abstract $\ldots \ldots \ldots \ldots \ldots \ldots \ldots \ldots \ldots \ldots$ ii

Reactor Radiation Division $\ldots \ldots \ldots \ldots \ldots \ldots \ldots \ldots \ldots \ldots$

Organization Charts $\ldots \ldots \ldots \ldots \ldots \ldots \ldots \ldots \ldots \ldots$

Research, Engineering, and Technical Staff . . . . . . . . . . . . 10

Description of Technical Activities . . . . . . . . . . . . 15

Reactor Operations and Services ................. 16

Neutron Condensed Matter Science . . . . . . . . . . . . . . . 18

Cold Neutron Project $\ldots \ldots \ldots \ldots \ldots \ldots \ldots \ldots \ldots$

Independent Programs $\ldots \ldots \ldots \ldots \ldots \ldots \ldots \ldots \ldots \ldots \ldots \ldots \ldots$

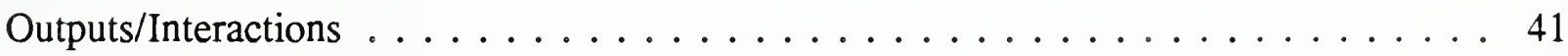

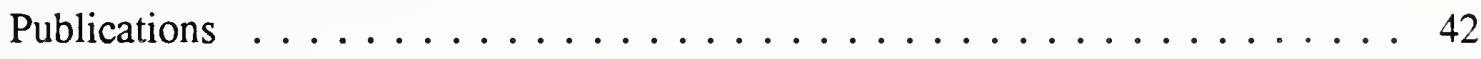

Technical and Professional Committee Participation and Leadership . . . . . . . . . . . . . . . . . 52

Industrial and Academic Interactions $\ldots \ldots \ldots \ldots \ldots \ldots$

Associated Activities . . . . . . . . . . . . . . 56 
1

I

I

I

I

,

I

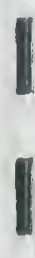

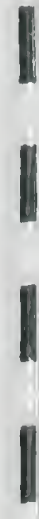




\section{J. Michael Rowe, Chief}

Tawfik M. Raby, Deputy Chief

The responsibilities of the Reactor Radiation Division are threefold: to operate the research reactor (NBSR) in a cost-effective manner while protecting the public safety; to conduct a program of materials research using neutron methods, while developing and maintaining state-ofthe-art instrumentation to ensure the best utilization of the NBSR as a NIST and national resource; and to develop and operate the Cold Neutron Research Facility as a National User Facility, providing unique measurement capabilities to U.S. researchers.

In order to fulfill these responsibilities, the Reactor Radiation Division (RRD), in collaboration with other researchers in the Materials Science and Engineering Laboratory (MSEL), other NIST centers, and many outside organizations, develops and applies neutron methods to a broad range of problems of national concern. These include the use of activation and other nuclear methods for chemical analysis, the characterization of the submicroscopic structure and dynamics of materials (e.g., hydrogen in metals, polymers, ceramics, alloys, magnetic materials, amorphous systems, micelles, microporous materials), the determination of residual stress and texture in materials, the use of neutron radiography to examine large components, the establishment of neutron flux and personnel radiation standards, and the development of a Cold Neutron Research Facility (CNRF).

The sections that follow are a summary of the technical activities of the Reactor Radiation Division over the past year. These activities are covered in much greater detail in a NIST Technical Note entitled NIST Reactor: Summary of Activities July 1989 through June 1990, which should be consulted for further details.

\section{Major Activities:}

In addition to operating the reactor, the Reactor Operations group is responsible for sample irradiations, both for Activation Analysis and isotope production. Once the materials are irradiated, other groups (either from NIST or outside organizations) are responsible for the analysis and scientific evaluation. The Center for Analytical Chemistry (CAC) is responsible for the majority of the Activation Analysis work, which provides a very sensitive technique for the determination of trace elements at very low concentrations. The method is extensively applied to the characterization of Standard Reference Materials (SRM's), to environmental studies, and to other problems such as stoichiometry in ceramic superconductors. In addition, CAC develops novel applications of nuclear methods for analtyical chemistry needs, such as neutron depth profiling and prompt gamma activation analysis. Many outside agencies (e.g., FDA, FBI, Treasury, EPA) make use of the activation and analysis capabilities developed by RRD and CAC. As part of the CNRF, CAC is working with RRD to develop greatly improved Depth Profiling and Prompt Gamma capabilities. 
RRD staff, in collaboration with many researchers from MSEL, NIST, other government agencies, universities, and industry, carry out an active program of research on materials characterization, and develop and maintain a state-of-the-art suite of neutron scattering instrumentation. The emphasis is on the study of new materials of importance to science and technology such as polymer blends, composites, electronic and structural ceramics, chemical catalysts, novel magnetic systems, thin films and interfaces, biological materials, and new metal alloys. This work involves more than 300 researchers from outside the Division, working both collaboratively and independently. At the present time, the NIST reactor has more users than any other facility for neutron research in the U.S., even before the CNRF is completed. As an essential part of this base research program, the Division staff are also responsible for the ongoing development of new applications of neutron methods and new instrumentation necessary to maintain the NBSR at the forefront of neutron research.

RRD staff also develop and apply neutron methods to problems in Non-Destructive Evaluation (NDE), such as the determination of residual stress in bulk specimens, measurement of texture in formed metals, and other areas. The technique of autoradiography, in which activation of elements in an artifact are used to determine elemental composition as a function of position is applied to study rare paintings, both for research and restoration purposes.

The Center for Radiation Research (CRR) carries out a program in radiation standards and measurement using the facilities at the NBSR. Through the use of double fission chambers and a series of accurately calibrated fission foils, they provide the basis for reactor neutron flux and power density measurements needed in the U.S. reactor development program. The calibration and intercomparison of the series of standard fission foils makes use of standard reference neutron fields established in the thermal column of the NBSR. CRR also maintains well characterized filtered beams of 2,25 , and $144 \mathrm{keV}$ in the reactor through tubes for the calibration and development of personnel neutron dosimeters.

A major element of the Division mission is centered in the Cold Neutron Project, with the goal of providing a critical new measurement capability for U.S. researchers. This multiyear project makes use of the large volume cold source installed into the reactor in 1987 by providing seven neutron guides (analagous to fiber optic light pipes, except for a difference in scale) to conduct large $(6 \times 15 \mathrm{~cm})$ beams into a newly constructed experimental hall that provides $20,000 \mathrm{sq}$. $\mathrm{ft}$. of new experimental space. In this hall, fifteen experimental stations are being installed to provide new cold neutron experimental capability not currently available anywhere in the U.S. Several non-RRD groups are involved in this effort, including CAC, the Center for Atomic, Molecular and Optical Properties (CAMOP), Exxon Research and Engineering Co., Eastman Kodak Company, Sandia National Laboratory, the National Science Foundation, and several universities. The CNRF will be operated as a National User Facility, with a large fraction of the experimental time allocated by a Program Advisory Committee. 
Reactor Utilization:

The NBSR is a National Center providing neutron measurement capabilities to researchers in MSEL, NIST and many other government agencies, industries and universities all over the U.S. Interactions with other scientists and organizations take the form of both collaborative efforts and independent programs which rely on utilization of the reactor and facilities provided by the NBSR staff. The extent of such interactions for FY 90 are indicated in the tables below. The number of personnel shown in Tables 1 and 2 include many short-term collaborators as well as permanent government, university or industrial guest scientists. These numbers are constantly changing and so may not be exact.

Collaborative interactions are those in which workers from outside the RRD cooperate scientifically with RRD scientists on problems of mutual interest. These interactions are summarized in Table 1.

Many of the other agency, university, and industrial collaborators have worked with us regularly for many years. In many cases research participants provide research sample preparation or characterization, theoretical analysis or other special expertise to the neutron research activities. Most come from all over the world to spend a few days, weeks, or months to carry out specific experiments using the facilities available at the NBSR. Collaborative programs include measurements on new magnetic materials and superconductors, fast-ion conductors, polymers, and biological molecules, thin films, catalytic and microporous materials, hydrogen in metals, voids and precipitates in alloys and ceramics, etc.

Table 1. Collaborative Interactions

No. of Personnel

FY 90

RRD Research Staff

Non-RRD Participants

Other NIST

Other Agency

University

126

Industrial

International

$\underline{66}$

Total Non-RRD

326

Independent programs are those programs carried out independently of the Reactor Radiation Division scientific staff by other NIST Divisions and outside organizations. Table 2 summarizes these interactions. 


\section{Table 2. Independent Programs}

\section{No. of Personnel}

FY 90

Other NIST

Other Agencies

Universities

Industrial

International
39

28

37

16

19

These tables demonstrate the extensive utilization of the NIST reactor by scientists and engineers from outside the Division. They come from 15 NIST Divisions and offices, 19 other Federal organizations, 53 U.S. universities, 27 U.S. industrial laboratories, and 34 foreign laboratories. 


\section{FY 90 Representative Accomplishments:}

o The NIST Reactor resumed operation on April 8, 1990. Installation of two of the initial three cold neutron guides has been completed in the guide hall.

o The University of Minnesota and its Center for Interfacial Science have agreed to participate with the Reactor Radiation Division in the development and use of two highresolution instruments at the Cold Neutron Research Facility (CNRF): the 30-meter Cold Neutron Small-Angle Scattering Spectrometer and the Cold Neutron Reflectometer. These instruments are expected to play a major role in the elucidation of the structure and microstructure of polymers and other materials as well as surface and interfacial structure and interactions - areas of considerable interest both to scientists of the University of Minnesota and NIST.

- Maximum entropy techniques have been used to produce an electron density map of the known structure of the biological macromolecule native bovine chymosin that is in remarkable agreement with the conventionally refined structure from a much larger data set including data from heavy-atom substituted specimens. This achievement opens the way to a major advance in the ability to determine the phases ab initio from native protein data.

The Reactor Radiation Division of NIST in cooperation with Optoline Associates, Ovonics Co. and ORNL have made a major breakthrough in a joint program of research and development of the neutron optical devices known as supermirrors. These vapordeposited, layered structures transport neutron beams from reactor (or other) source to experimental station with significantly increased intensity relative to conventional guides. Supermirror reflectivities have now been produced with critical angles three times that obtained using an ordinary $\mathrm{Ni}$ film. These results will play a major role in re-establishing the U.S. as the leader in materials research with neutrons.

- Recent quasielastic neutron scattering studies of hydrogen dynamics in rare earth metals (in collaboration with the Paul Scherrer Institute) have revealed the existence of very rapidlow temperature "hopping" of protons in $\alpha$-phase $\mathrm{ScH}_{x}$ and $\mathrm{Y}-\mathrm{H}_{x}$. The results reveal a pronounced quasielastic linewidth minimum near $100 \mathrm{~K}$ and an increase at lower temperatures indicative of non-adiabatic behavior associated with weak coupling of hydrogen to the metal conduction electrons. This is the first such observation for a pure metal-hydrogen system.

IBM has agreed to participate with the Reactor Radiation Division in the development and use of the cold neutron reflectometer at the Cold Neutron Research Facility (CNRF). Neutron reflectometry measurements at relatively low sensitivities have already provided important information on surface, interfaces and thin films for systems as diverse as magnetic films, multi-layers and di-block copolymers.

o The Center for Materials Science and Engineering at MIT has agreed to participate with the Reactor Radiation Division in the development and use of a new 32-detector, ultra-high resolution diffractometer for materials research at the NIST Reactor. The new instrument 
will be a world-class diffractometer with state-of-the-art capabilities in resolution, versatility, and data collection efficiency. Of particular initial interest in the collaborative program are structural studies of graphite intercalation compounds and fast-ion conductors and advanced ceramics.

- In April, Neutron Group scientists commissioned a new thermal neutron reflectometer, which is currently the best instrument of its kind in the world. First results include the achievement of $\sim 2 \times 10^{-7}$ reflectivity in studies of polymer thin-films and the first observation of a surface magnetic diffraction peak by grazing-angle neutron diffraction.

o The Reactor Radiation Division is collaborating with engineers of the Society of Automotive Engineers in a multiaxial fatigue lifetime prediction project, part of an integrated engineering approach for design analysis and validation of components for vehicles. Neutron diffraction is being employed in this application because it is nondestructive, and because the penetrating power of neutrons allows probing of residual stresses virtually to the center of the $40 \mathrm{~mm}$ diameter test axles. This collaboration represents an ideal application of neutron diffraction as a reference method for e.g., ultrasonics or (destructive) x-ray diffraction techniques.

RRD scientists have developed a magnetoelastic formalism for rare earth artificial metallic superlattices which predicts the dependence on epitaxial strain of the ferromagnetic to helical phase transition temperature and, equivalently, the magnitude of applied field required to artificially induce this transition. This theoretical result has recently been confirmed in experiments on new superlattices or dysprosium interleaved with nonmagnetic lutetium.

Scientists from DuPont, SUNY (Stony Brook) and the Reactor Radiation and Ceramics Divisions of NIST have begun a new collaborative program in the area of high $\mathrm{T}_{c}$ superconductors. New phases of compounds in the phase diagrams of strontium oxide, calcium oxide, bismuth oxide and copper oxide have been synthesized, and their crystal structures are being determined to very high precision by means of neutron and $\mathrm{x}$-ray diffraction. Elucidation of the structures of these new phases is directly related to the crystal chemistry, phase equilibria and stability of the most important high $T_{c}$ superconductors discovered to date.

o In our Materials Structure Data program, theory, algorithms and computer programs have been developed during the past year to establish extensive networks of material interrelationships within and between scientific databases. Computer files with cross references have been calculated that have many applications in materials characterization and design and database enhancement. 


\section{Organization Chart and Research Staff}



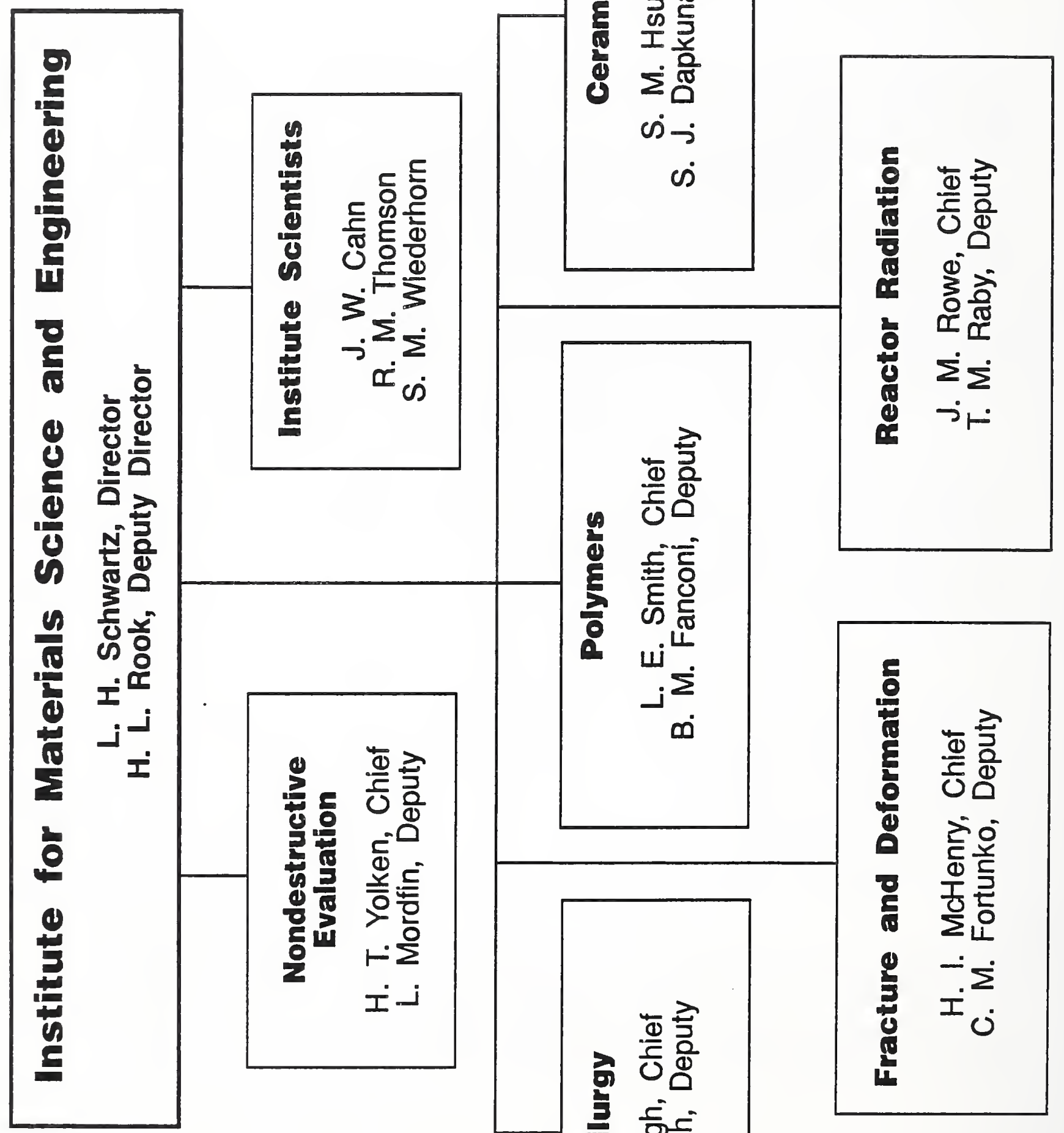


\section{PERSONNEL ROSTER}

\section{REACTOR RADIATION DIVISION}

J. M. Rowe, Chief

T. M. Raby, Deputy

H. J. Prask, Sci. Ass't

E. C. Maxwell, Admin. Officer

S. L. Neal. Admin. Asst.

\section{REACTOR OPERATIONS} \& ENGINEERING

T. M. Raby, Chief

J. F. Torrence, Deputy

J. H. Nicklas, Chief Eng.

A. Wise, Sec'y

C. M. Sweeney, Sec'y
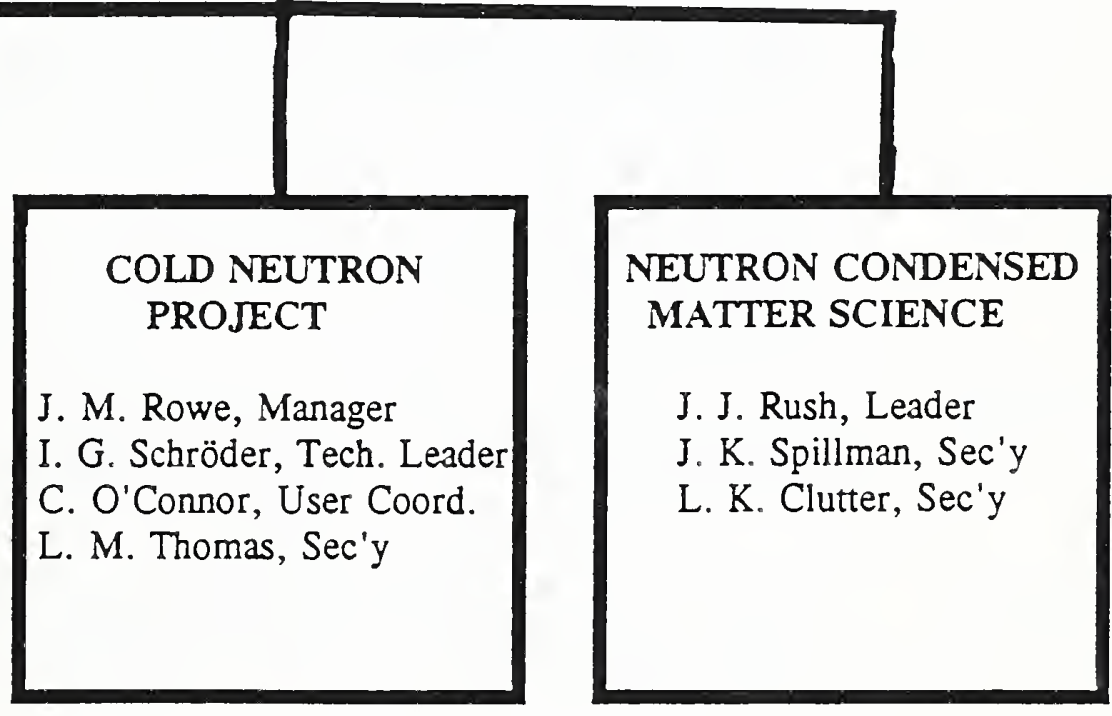
J. F. Ankner o Condensed matter physics

- Neutron reflectometry and grazing-angle diffraction

o Instrument development

N. F. Berk o Condensed matter theory

- SANS theory for microstructure analysis

o Computer software for graphics and data analysis

J. A. Borchers o Thin film analysis

- Artificially modulated materials

o Magnetism

R. C. Casella o Theory of neutron scattering from light-atom defects in metals

- Group theory analyses of neutron scattering from condensed matter

o Elementary particle theory, especially as related to reactor generated experiments

R. S. Conway o Electronic engineering

o Nuclear instrumentation

J. R. D. Copley o Time-of-flight spectrometer development

- Neutron instrumentation conceptual design

o Condensed matter physics

W. E. Dickerson o Neutron scattering instrumentation

- Microcomputer interfacing

o Nuclear and engineering physics

R. W. Erwin o Magnetic materials

- Phase transformations

o Spin echo techniques

o Cryogenics

C. J. Glinka o SANS microstructure of metals and porous media

o Magnetic materials

o Cold neutron instrument development

J. A. Gotaas o Magnetism and phase transformations

- Cold neutron sources

o SANS instrumentation and research

P. H. Graham o Engineering design

G. C. Greene o System and user software for cold neutron instrumentation

o Spectrometer and data acquisition systems interfaces

B. Hammouda o SANS from polymer systems

- Quasielastic scattering from polymer solutions

o SANS instrument development 
V. L. Himes o Crystal database development

o X-ray crystallography

P. A. Kopetka o Mechanical engineering

o Cold Source design

o Electro-mechanical systems

S. Krueger o Small angle neutron scattering instrumentation

o Microstructure of materials

o Biological problems

J. G. LaRock o Mechanical engineering

o Neutron instrumentation design

H. P. Layer o Electronics and data processing

o Advanced instrumentation

o Fundamental physics

J. W. Lynn o Condensed matter physics

o Magnetic materials

o Neutron scattering methods

C. F. Majkrzak o Condensed matter physics

o Polarized neutron scattering

o Polarizing and monochromating devices

A. D. Mighell o Crystallographic database development

o Single crystal diffraction

o Theory of crystal lattices

B. Mozer o Structure and microstructure of metallic glasses

o Dynamics of liquids

o NDE of alloys

D. A. Neumann o Condensed matter physics

o Two-dimensional materials

o Neutron and $\mathrm{x}$-ray scattering instrumentation

J. H. Nicklas o Mechanical engineering

o Reactor fuel design

o Reactor engineering support

D. J. Pierce o Mechanical engineering

o Neutron instrumentation design

H. J. Prask o Residual stress measurement

o Neutron NDE hardware

o Neutron NDE instrumentation 
E. Prince

T. M. Raby

J. J. Rhyne

J. M. Rowe

J. J. Rush

A. Santoro

S. K. Satija

I. G. Schröder

o Cold neutron instrumentation development

o Nuclear and engineering physics

o Optical devices for neutron transport

J. K. Stalick

o Neutron and x-ray diffraction

o Inorganic chemistry

o Crystal database development

J. B. Sturrock

o Design engineering

o Nuclear systems and components

M. Suthar

J. F. Torrence

T. J. Udovic o Design engineering

o Nuclear systems and components

o Reactor supervision

- Reactor maintenance

o Nuclear engineering

o Neutron time-of-flight instrumentation

o Properties of catalysts

o Spectroscopy of surfaces 
R. E. Williams

o Cold neutron source development

o Nuclear engineering

\section{TECHNICAL STAFF}

\section{Reactor Operations}

Richard D. Beasley

Myron H. Bell

Nathan A. Bickford

Mark G. Cassells

Forrest C. Clark

Howard W. Dilks

Daniel J. Flynn

Larry T. Lindstrom
Michael J. McDonald

William W. Mueller

Thomas J. Myers

John H. Ring

Ricky P. Sprow

Robert F. Stiber

Attila L. Toth

Daniel P. Wilkison

Kevin I. Wright

\section{Neutron Research}

George M. Baltic

David Clem

Donald H. Fravel

Thomas Green

Wayne C. Knill

Michael J. Rinehart
David Roeseler

William H. Rymes

Dan Swearingen

Thuan Thai

Robert H. Williams

Reactor Engineering

James A. Beatty

Richard P. Hayes 


\section{Description of Technical Activities}

The technical activities of the Division are summarized in this section. A more detailed description of each project can be found in the NIST Technical Note "NIST Reactor, Summary of Activities July, 1989 through June, 1990." 


\section{REACTOR OPERATIONS AND ENGINEERING}

\section{T. M. Raby, J. F. Torrence, J. H. Ring, and N. A. Bickford \\ (Reactor Operations \& Services) and \\ J. H. Nicklas and R. S. Conway (Reactor Engineering)}

The extended shutdown period necessitated by the complex neutron guide installation procedures was used by both reactor operations and engineering to perform design modifications and improvements, major maintenance, and equipment repair. Highlights of significant activities are listed below, all of which were performed in-house by the operating and engineering staffs.

Confinement Building and Penetrations. Seven penetrations through 24-ft thick confinement building walls were drilled to accommodate the new guide tubes. Four penetrations were temporarily resealed for future tubes. Confinement isolation valves were installed in the remaining three penetrations currently in use. A complete control system for the operation of these valves was designed and installed. This included connection to the reactor safety system that would cause automatic closure and isolation of the confinement building upon a major scram signal. Both the operation and safety function of these valves, as well as their effect on confinement leak rate, were tested and the valves met all aspects of the technical specifications requirements on the first try. This is a significant milestone because of the complex design and the stringent requirements. The confinement building was completely refurbished. The experimental and operating floors were repainted with special sealant type paint. The building roof was replaced. Most of the asbestos used as insulation was removed and replaced with nonasbestos insulation.

Heavy Water, Fuel and Shim Arms. Both heavy water and enriched fuel are in extremely short supply in the United States. Because fuel utilization, which is already the best in the country, continues to improve further through innovative management and design, there is enough fuel on hand to last to the end of the decade. Negotiations with the Department of Energy resulted in a commitment of 36 tons of heavy water for future use. Three sets of shim arm blades, which are unique to the facility, are currently being assembled and should provide replacement for the next 15 years. Extensive maintenance was performed on all four shim arm drives. A test stand was designed and built to test the drives prior to installation. The stand provides for rapid and superior testing compared to that done in-place, which is cumbersome and time consuming. For some time, shim No. 2 would not return to the same position following a scram. After months of testing, the problem was traced to the inner bearing of the shim arm shaft. Finding the actual cause was in itself a significant accomplishment because the problem was elusive and nonrepetitive. Both the bearing and the heavy water seal were replaced with the core in place. This is the first time in the history of the facility that something of this critical nature was done and it could not have been performed better with minimal exposure and flawless operation.

Main Heat Exchangers. The extended shutdown was used to locate a very small leak (on the order of $0.0001 \mathrm{gpm}$ ) in one of the main heat exchangers. After extensive searching and testing, several tubes were plugged. This heat exchanger has been in service for more than 15 years and every effort is being made to extend its use until the replacement heat exchangers are obtained. 
Comprehensive specifications for new heat exchangers were completed and a successful request for proposals has been issued, generating several acceptable offers.

Cooling Tower. A major overhaul of the cooling tower was initiated and is near completion. This work included the replacement of nearly 1000 carbon steel bolts with stainless steel bolts.

Staffing. Extensive training was provided to the staff of 16 licensed senior operators in many technical areas as part of the new Nuclear Regulatory Commission (NRC) required requalification program. Two new operators will take their senior licensing examination scheduled for the end of the year by the NRC. One senior operator, who is a graduate electrical engineer, will then be transferred to Engineering to augment the small staff. The efforts and performance of the operating staff over the years received high recognition from the Department of Commerce with the unprecedented award of the Silver Medal to the entire group. 


\section{NEUTRON CONDENSED MATTER SCIENCE}

\section{MICROSCOPIC PROPERTIES OF CHEMICAL MATERIALS}

N.F. Berk, R.C. Casella, J.R.D. Copley, D.A. Neumann, J.J. Rush, T.J. Udovic, C. Bostoen ${ }^{1}$,P. Depondt ${ }^{2}$, W. Kamitakahara ${ }^{3}$, J. Nicol $^{3}$, B. Olivier ${ }^{4}$, S. Trevino ${ }^{5}$

${ }^{1}$ Guest Scientist, University of Antwerp

${ }^{2}$ Guest Scientist, University of Pierre et Marie Curie

${ }^{3}$ Guest Scientist, University of Maryland

${ }^{4}$ Guest Scientist, Sandia National Laboratories

${ }^{5}$ Guest Scientist, U. S. Army Armament Munitions, and Chemical Command

\section{CATALYSTS AND LAYERED MATERIALS}

During the past year we have continued our research on the structure and dynamics of adsorbed species inside porous frameworks, on surfaces and on intercalation compounds in order to elucidate details of the guest-guest and guest-host interactions.

A relatively new method of creating non-linear optical materials is by the adsorption of a guest species into a host imposing a symmetry restriction on the guest which creates a system whose optical properties are quite distinct for those of either the guest or host. A recent example of this is para-nitroaniline adsorbed into the channels of the molecular sieve ALPO-5. Here inelastic neutron scattering studies (with UCSB) at loadings of 3 and $13 \mathrm{wt} \%$ (the onset and the maximum of the non-linear optical coefficient) have shown a dramatic difference in the torsional excitation of the $\mathrm{NH}_{2}$ group due to differences in the alignment, ordering, and hydrogen bonding of the para-nitroaniline inside the one-dimensional channels. Work has also continued on the dynamics of ammonium ions in reammoniated zeolite rho which has a high degree of selectivity and activity for the synthesis of dimethylamine from ammonia and methanol. Here data taken at $80 \mathrm{~K}$ show a very broad quasielastic component which disappears at $10 \mathrm{~K}$ indicating a very weakly hindered rotation of some of the ammonium ions. We have used neutron diffraction to show that there are two distinct ammonium sites: one in the $\alpha$ - cage which is weakly bound and the other in the center of the double 8-rings which is more strongly coordinated to the framework oxygens. A program has been recently initiated to understand the active mechanisms and structural properties of various hydroxy-sodalites with varying degrees of hydration. A preliminary analysis of the diffraction data has yielded atomic positions of the hydroxyl groups, while inelastic neutron scattering has given information on the dynamics of both the $\mathrm{OH}$ groups and the water molecules, with the $\mathrm{OH}$ wag mode being clearly observed at about $70 \mathrm{meV}$.

During the past year work has also progressed on layered aluminosilicates (with the Colorado School of Mines and Michigan State University). Here porosity is not a feature of the structure, but is induced by exchanging large cations, such as tetramethylammonium (TMA), for the naturally occurring ions, e.g., Na. The resulting material is known as a "pillared clay" and the cations which prop the layers apart are referred to as "pillars". Here work has been concentrated on the barrier to rotation of the torsional modes of the methyl groups which we have shown to 
be inversely proportional to the volume available to the tetramethylammonium ion for a wide range of systems, including the TMA-halides and TMA occluded in various zeolite cages as well as TMA-clays. This indicates that the increased barrier is due to steric constraints. In a related development we have shown that the energy of the $\mathrm{OH}$ wag in these minerals is quite sensitive to the occupancy of the octahedral site. For complete occupancy the wag is found around 70-80 $\mathrm{meV}$ while when the octahedral site is $2 / 3$ occupied the energy is increased to $105-115 \mathrm{meV}$. It should also be noted that the energy of the $\mathrm{OH}$ wag observed for hydroxy-sodalite is quite similar to that obtained for the layered aluminosilicates having complete octahedral site occupancy. This is not surprising since the similar coordination of the hydroxyl group in these systems. Also, the first phonon spectra of a hydrated vermiculite sample has been obtained and shows a softening at the zone boundary of the in-plane transverse branch having in plane polarization, which is possibly related to the transition between hydration states.

Work has also continued on the structure and dynamics of alkali-metal ammonia complexes intercalated in graphite (with the Université Pierre et Marie Curie). Recent diffraction results on Cs-ammonia graphite show that the complexes are not as well defined as they are for Kammonia, however inelastic results show that the rotation-translation coupling is enhanced indicating that the mode which couples to the phonons is probably not related to the formation of the complexes. Measurements on $\mathrm{K}$-ammonia intercalated graphite show a dramatic change in the intensities of the $(00 \ell)$ reflections as a function of pressure indicating orientational ordering of the ammonia molecules. Inelastic scattering results indicate that this ordering is accompanied by an increase in the strength of the rotation-translation coupling.

Our studies of the dynamics of chemical species adsorbed on surfaces has also continued. A particular example of this work is the dynamics of trimethylsilyl adsorbed on silica (with the Center for Analytical Chemistry and PSI) which is used in reverse-phase liquid chromatography. In addition to the rotational motions of the entire $\left(\mathrm{CH}_{3}\right)_{3} \mathrm{Si}$ species and the $\left(\mathrm{CH}_{3}\right)_{3} \mathrm{Si}$ and methyl group torsional excitations at, we have observed a triplet in the vibrational spectra between 80 and $120 \mathrm{meV}$ due to $\mathrm{Si}-\mathrm{C}-\mathrm{H}$ and $\mathrm{H}-\mathrm{C}-\mathrm{H}$ bending excitations. Attempts to model this spectra seemed to require the introduction of surface adsorbate interactions. To test this hypothesis we have measured the vibrational spectra for hexamethyldisidoxane and polydimethylsiloxane, and except for a slight shift in energy the triplet is essentially identical indicating that it is intrinsic to the $\left(\mathrm{CH}_{3}\right)_{3} \mathrm{Si}$ group. Further attempts to model the data are in progress.

\section{MOLECULAR SOLIDS AND GLASSES}

The role of disorder in determining the physical properties of solids has been a major theme of condensed matter science for some time. During the past year our research on disordered systems has focussed primarily on substitutional disorder particularly of ammonium ions for alkali metals and on the structure and dynamics of amorphous solids.

It has recently been shown that the non-linear optical properties of K-titanyl phosphate and $\mathrm{K}$ titanyl arsenate may be altered by replacing some of the $\mathrm{K}$ ions with ammonium ions. We have therefore measured (with UCSB) vibrational spectra and quasielastic spectra of a series of $\mathrm{K}_{1-x}\left(\mathrm{NH}_{4}\right)_{x}$ compounds, in order to correlate the dynamics of the ammonium ion with the optical properties and the structure as determined by neutron diffraction. In all samples studied to date, 
the torsional mode of the ammonium ion was found in the range $35-50 \mathrm{meV}$, indicating a barrier to rotation on the order of $100 \mathrm{meV}$; analysis of the quasielastic data is just beginning.

Work has also been performed on the substitutionally disordered compound $\mathrm{K}_{1-x}\left(\mathrm{NH}_{4}\right)_{x} \mathrm{I}$ (with the University of Antwerp). For this system neutron diffraction for $\mathrm{x}=0.40$ has revealed that the observed electric dipole moment of the ammonium ion is due to a distortion of the ion from its ideal tetrahedral shape. The dipole moment of $1.3 \pm 0.2 \mathrm{D}$ extracted from the deformation is in agreement with earlier dielectric results. X-ray scattering has also been used to determine a partial phase diagram for this system for high ammonium concentrations. This work has shown that there is a critical concentration, where the phase transition from the $\mathrm{NaCl}$ structure to the $\mathrm{CsCl}$ structure is suppressed, at $\mathrm{x}_{c} \approx 0.77$. Thus as the concentration of spherical $\mathrm{K}$ impurities is increased, the transition temperature is reduced similar to the situation in $\mathrm{K}(\mathrm{CN})_{x} \mathrm{Br}_{1-x}$.

Experiments have recently been initiated on alkali-silicate glasses (with Sandia National Laboratories). The addition of $\mathrm{K}_{2} \mathrm{O}$ to $\mathrm{SiO}_{2}$ produces glasses in which the silicate network is disrupted by non-bridging oxygen atoms, causing the glass transition temperature to be lowered. Rather dramatic structural changes have been observed using elastic neutron scattering. Inelastic measurements will be performed soon. It should then be possible to relate these properties to current models based on constraint counting and average atomic coordination. Vibrational spectra have already been measured (with Penn State and Ohio Universities) for two different types of disordered carbon and the results have been compared to the spectra of polycrystalline diamond and graphite. These results show that so-called "glassy carbon" has a vibrational density of states which is essentially an energy-broadened form of the graphite density of states. This suggests that "glassy carbon" is graphitic and that it may be more correctly termed "microcrystalline graphite", consistent with the generally held view. The second type of disordered carbon was an amorphous material produced by sputtering. This displayed an almost featureless density of states except for many low energy modes, reminiscent of the density of states of graphite, indicating that this sample is primarily three-fold coordinated. However both the vibrational spectrum and the diffraction pattern identify this material as a true continuous random network. The fact that the low energy density of states of this material is similar to that of graphite, despite the absence of layering, is further evidence that the low energy density of states is mainly determined by the average coordination number while details of the network connectivity are of secondary importance.

\section{HYDROGEN IN METALS}

Research in this area during the past year has focussed on extended studies of anomalous hydrogen dynamics and anisotropic potentials in hcp rare-earth metal-hydrogen systems (with the Paul-Scherrer Institute). Our neutron quasielastic scattering results on localized motion of $\mathrm{H}$ in $\alpha$-phase $\mathrm{ScH}_{x}$ show a "hopping" rate between near-neighbor tetrahedral sites along the c-axis exceeding $\sim 10^{11} \mathrm{sec}^{-1}$ over the entire temperature range $(10-300 \mathrm{~K})$ and a remarkable upturn below $100^{\circ} \mathrm{K}$. Moreover, the quasielastic width shows an approximately $\mathrm{T}^{-1}$ behavior indicative of a Kondo-like weak interaction with the conduction electrons. These scattering results, along with our very recent similar results for the $\mathrm{YH}_{x}$ system, can be well reproduced over the entire temperature range with a model assuming a changing admixture of labile ("hopping") and nonlabile protons, separated by energies in the range of $80 \mathrm{meV}$. These observations of very rapid 
low temperature tunneling are the first ever obtained for hydrogen in a pure metal and are analogous to recent experimental results for protons trapped by impurities in refractory metals. Further work is underway to probe the local $\mathrm{H}$ potential in Scandium by isotope dilution spectroscopy and to study the details of c-axis short range ordering of the protons in yttrium by neutron diffuse scattering and Huang scattering.

Work has also continued on neutron spectroscopic studies of dilute hydrogen trapped in disordered bcc $\left(\mathrm{Nb}_{x} \mathrm{~V}_{1-x} \mathrm{H}_{y}\right)$ and fcc $(\mathrm{PdScHx})$ alloys and in alloy glasses. Complete analysis of the $\mathrm{Nb}_{x} \mathrm{~V}_{1-x} \mathrm{H}_{y}$ system results have revealed an unusual temperature and concentration-dependent distribution of $\mathrm{H}$ atoms among both octahedral and tetrahedral type sites. This is the first bcc system for which octahedral $\mathrm{H}$ site occupation has been observed. The neutron results are in clear disagreement with recent interpretations of extensive thermodynamic measurements on this disordered alloy system. 


\section{NEUTRON SCATTERING IN SUPERCONDUCTING, LAYERED, AND AMORPHOUS MAGNETIC MATERIALS \\ J.J. Rhyne, R.W. Erwin, J.A. Borchers ${ }^{1}$, J.A. Gotaas, J.K. Stalick, B. Mozer, J.W.

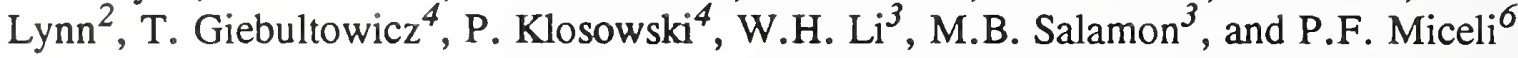 \\ ${ }^{1}$ NAS-NRC Postdoctoral Associate \\ ${ }^{2}$ Consultant, University of Maryland \\ ${ }^{3}$ Guest Scientist, University of Maryland \\ ${ }^{4}$ Guest Scientists, University of Notre Dame \\ ${ }^{5}$ Guest Scientist, University of Illinois \\ ${ }^{6}$ Guest Scientist, Bellcore}

\section{LAYERED MAGNETIC MATERIALS}

Magnetoelastic Effects in Rare Earth Artificial Superlattices. The mechanism behind the occurrence of various periodic to ferromagnetic phase transitions in the rare earth metals has been a subject of intense theoretical and experimental interest. Theoretical calculations dating back more than 15 years suggested that these transitions are driven by magnetoelastic forces; however, until the advent of the present artificial superlattice studies, this prediction could not be studied definitively by experiment. Because of the epitaxial strain constraints induced by both the substrate layers and the non-magnetic intervening layers grown between magnetic layers, superlattices offer the opportunity to tailor make materials with specific strain states. We have developed a theoretical formalism which provides an expression for the critical fields necessary to drive the ferromagnetic phase transition as a function of the lattice mismatch strain between the two dissimilar layers. In particular for Dy and Er layers interleaved with $\mathrm{Y}$ layers, the predicted critical fields increase with lattice mismatch strain. The effect is much weaker for Dy systems than for Er superlattices which has been confirmed in some detail experimentally in neutron scattering experiments on both epilayers and full artificial superlattices. An interesting result of the calculation is that superlattices in which the non-magnetic intervening layer is Lu instead of Y should show a negative "lattice clamping" strain leading to a reduction in the critical transition field below the value observed in bulk Dy or Er at the same temperature. Likewise these Lu systems would be expected to exhibit an increase in the temperature at which the Dy or Er spins spontaneously order into a ferromagnetic configuration in zero applied field. Preliminary results on Dy|Ly superlattices have confirmed this prediction, in particular a $\left[\mathrm{Dy}_{15.5} \mid \mathrm{Lu}_{22}\right]_{75}$ superlattice shows only ferromagnetic order with no evidence of the helical phase seen in bulk Dy and in the Dy /Y superlattices. Details of the ordering temperatures and reduced critical fields are currently being compared to the quantitative predictions of the magnetoelastic theory.

Magnetic Semiconductor Films and Artificial Superlattices. The advent of molecular beam epitaxy methods has enabled the production of highly perfect single crystal films and artificial superlattices of 3-5 and 2-6 semiconductors. Our current studies are concerned with layered $\mathrm{ZnSe} \mid \mathrm{MnSe}$ and $\mathrm{ZnTe} \mid \mathrm{MnTe}$ materials which exhibit magnetic properties which are in many respects vastly different from the equivalent bulk magnetic semiconductor alloys. Because of the lattice mismatch, these systems exhibit large epitaxial strains which affect both the atomic 
structure and magnetism -- for example all the Mn based chalcogenide layers form single crystals of the Zinc Blende structure and show type III antiferomagnetic order. The only bulk system showing the same structure is $\beta \mathrm{MnS}$ which is stable only in polycrystalline form. In studies of $\mathrm{ZnSe} \mid \mathrm{MnSe}$ superlattices with from 3 to 15 atomic planes of MnSe, magnetic order was routinely observed, but there was no evidence of long range couplings existing across the non-magnetic $\mathrm{ZnSe}$ layers (c.f. the rare earth systems above). The samples with the thinner MnSe layers exhibited some evidence of a cross-over into the $2 \mathrm{~d}$ magnetic regime.

Zinc-blend MnSe can either be grown as unstrained thick single bilayers or as a strained $\mathrm{ZnTe} \mid \mathrm{MnTe}$ superlattice. Such a system allows one to probe directly the effects of epitaxial strain on the magnetic properties. The strained superlattices exhibit properties quite similar to $\mathrm{ZnSe} \mid \mathrm{MnSe}$ except with a lower $\mathrm{T}_{N}$ due to weaker exchange. However, the relatively unstrained single layers of $\mathrm{MnSe}$ exhibit a first order phase transition between paramagnetic and antiferromagnetic states in contrast to the second order transition seen in the other superlattice systems and in bulk materials.

\section{HIGH $\mathrm{T}_{c}$ SUPERCONDUCTORS, MAGNETIC EFFECTS, AND MAGNETIC AND NON- MAGNETIC ATOMIC SUBSTITUTIONS}

Effects of Gold Substitution into 1-2-3 Superconductor Materials. NIST results have previously shown that atoms such as $\mathrm{Al}, \mathrm{Ga}$, and $\mathrm{Co}$ which are of $3^{+}$valency when substituted for $\mathrm{Cu}$ in concentrations of a few per cent in the $\mathrm{YBa}_{2} \mathrm{Cu}_{3} \mathrm{O}_{7}$ superconductors always displace $\mathrm{Cu}$ from the chain $[\mathrm{Cu}(1)]$ site, while $\mathrm{Zn}^{++}$substitutes on the plane $[\mathrm{Cu}(2)]$ site, and $\mathrm{Fe}$ and possible $\mathrm{Mn}$ go to both sites. All such substitutions have a deleterious effect on the superconducting $\mathrm{T}_{c}$ with the resulting reduction from the plane site substitutions much more dramatic than that from the chain site atoms. Previously $\mathrm{Au}$ has been thought to be inert as far as incorporation into $\mathrm{YBa}_{2} \mathrm{Cu}_{3} \mathrm{O}_{7}$; however collaborators at John Hopkins University found that by adding excess Au to already stoichiometric material, the Au would dissolve and produce a very unusual effect in that it is the only subsituent which actually raises $\mathrm{T}_{c}$ (about $1.5 \mathrm{~K}$ with $10 \%$ added $\mathrm{Au}$.) This result quickly prompted questions of the site occupation of the Au atoms. Unfortunately, neutron scattering, which is the scattering method of choice since it is quite sensitive to oxygen atoms, was severely compromised because of the nearly identical scattering amplitudes of $\mathrm{Au}$ and $\mathrm{Cu}$. However, a newly developed crystal structure refinement technique involving combined $\mathrm{x}$-ray and neutron diffraction, was able to show that the $\mathrm{Au}$ substituted only for the $\mathrm{Cu}(1)$ [chain] site $\mathrm{Cu}$ leaving free excess $\mathrm{Cu}_{2} \mathrm{O}_{3}$. The substitution also resulted in the distortion of $\mathrm{Cu}-\mathrm{O}$ bond distances and a slight oxygen excess (over $\mathrm{O}_{7}$ ) as shown from the refinement. These results have significant impact on the use of $\mathrm{Au}$ crucibles for the preparation of "pure" $\mathrm{YBa}_{2} \mathrm{Cu}_{3} \mathrm{O}_{7}$ single crystals.

Magnetic Interactions in Mn-substituted Bismuth-based Materials. The compound $\mathrm{Bi}_{2} \mathrm{Sr}_{2} \mathrm{MnO}_{6+y}$ is a material analogous to a high temperature superconductor of the same formulation but containing $\mathrm{Cu}$. In this case the $\mathrm{Mn}$ ion substituted for $\mathrm{Cu}$ can be used as a probe of the relationship of structure and magnetism. The $\mathrm{Mn}$ ions are well separated $(\approx 12 \mathrm{~A})$ resulting in a $2 \mathrm{~d}$ magnetic structure. Single crystal neutron diffraction studies revealed that the Mn orders with one domain having wave vector perpendicular to the structural modulation direction when the material is cooled in zero applied field, and that a second domain also forms, ordered along the structural modulation direction, on application of a magnetic field. A detailed analysis of the 
diffraction data indicates that the structural modulation induces weak ferromagnetism and that the field-induced effect arises from the re-stacking of the magnetic layers -- antiferromagnetic at zero field and ferrimagnetic at high field.

Magnetic Interactions in Other Oxide Superconductors. Another area of interest concerns the magnetic properties of the high $\mathrm{T}_{c}$ oxide superconductors. There are two important aspects to the magnetism in these systems. The first involves the magnetic ordering and spin fluctuations associated with the $\mathrm{Cu}$ ions in these materials. In the superconducting regime we have observed fluctuating moments, primarily through small angle neutron scattering measurements on the 1-2-3 materials. These fluctuations are strongly suppressed below the superconducting transition temperature. In the oxygen-deficient insulating phase, on the other hand, the $\mathrm{Cu}$ moments exhibit long range antiferromagnetic order, with energetics which are an order of magnitude larger than the phonon energies in these materials. The second area of interest concerns the nature of the rare earth ordering in these 'magnetic superconductors'. In the 1-2-3, 2-4-8, and 2-4-7 class of materials the rare earth sublattice is effectively decoupled electronically from the superconducting electrons, and these materials offer some of the best examples of two-dimensional magnets known in nature. For example, the $\mathrm{ErBa}_{2} \mathrm{Cu}_{3} \mathrm{O}_{7}$ is a prototype $\mathrm{S}=$ $1 / 2,2 \mathrm{D}$ Ising system. In the electron-type superconductors such as (Nd-Ce) ${ }_{2} \mathrm{CuO}_{4}$, on the other hand, the rare earth and $\mathrm{Cu}$ sublattices are strongly coupled, and this coupling directly influences both the magnetic and superconducting properties. One of the fundamental questions for the high $\mathrm{T}_{c}$ materials concerns the origin of the electron pairing in the superconducting state. Because of the strong energetics of the $\mathrm{Cu}$ spin system, a magnetic interaction mechanism is a leading contender for the correct explanation. However, even if magnetism is not the origin of the superconductivity in these high $\mathrm{T}_{c}$ materials, it is quite clear that the $\mathrm{Cu}-\mathrm{O}$ layers are intimately involved in both the magnetism and superconductivity, and the striking magnetic behavior these materials display is of fundamental interest in its own right. 


\title{
3. NEUTRON DIFFRACTION METHODS AND APPLICATIONS
}

\author{
E. Prince, A. Santoro, J. Stalick, B. Mozer, H. Prask, C. Choi ${ }^{1}$, \\ O. Elsenhans ${ }^{2}$, Q. Huang ${ }^{3}$ \\ ${ }^{1}$ Guest Scientist, Army Armament Munitions and Chemical Command \\ ${ }^{2}$ Guest Scientist, Paul Scherrer Institute \\ ${ }^{3}$ Guest Scientist, Fujian Institute of Research, People's Republic of China
}

Crystallographic research during the past year has again covered diverse applications ranging from solid state and organic chemistry to metallurgy and materials science to protein crystallography. Extensive studies of the structural chemistry and related properties of high $\mathrm{T}_{c}$ superconductors included a neutron structure determinations (with AT\&T Bell Labs) of a new compound, $\mathrm{La}_{1.6} \mathrm{Sr}_{0.4} \mathrm{CaCu}_{2} \mathrm{O}_{6}$ which becomes superconducting through the introduction of carriers by straightforward atomic substitution, without the intervention of complex charge reservoir layers and another series of experiments (with Bell Labs and U. of Grenoble) to probe the details of atomic ordering, oxygen distributions, and twinning effects in a new superconducting series $\left(\mathrm{Pb}_{2} \mathrm{Sr}_{2} \mathrm{Y}_{1-x} \mathrm{Ca}_{x} \mathrm{Cu}_{3} \mathrm{O}_{8+\delta}\right)$. Work has also been carried out with DuPont to reveal the oxygen ordering and vacancy distributions which are a key to understanding newly discovered bismuth (III) strontium oxide compounds.

Other structure research by high resolution powder diffraction include work with the Ceramics Division in conjunction with phase equilibrium studies of the $\mathrm{BaO}\left(\mathrm{BaCO}_{3}\right)-\mathrm{NdO}_{3}-\mathrm{CuO}$ system; studies of the aerospace alloy, $\mathrm{Ti}_{2} \mathrm{AlNb}$ (with GE) which established the complex arrangement of $\mathrm{Ti}$ and $\mathrm{Nb}$ atoms in this material; and an investigation (with MIT) of the anion and cation disorder associated with the ionic conduction mechanism in the pyrochlore system

$\mathrm{Y}_{2}\left(\mathrm{Zr}_{x} \mathrm{Ti}_{1-x}\right)_{2} \mathrm{O}_{7}$. Powder diffraction techniques were also used to establish the structural distortions leading to a dipole moment for $\mathrm{NH}_{4}{ }^{+}$ions in mixed salts, $\mathrm{K}_{1-x}\left(\mathrm{ND}_{4}\right)_{x} \mathrm{I}$ and to test a new method for reproducible preparation of icosahedral quasicrystals. Final design and almost all construction has been completed for a new state-of-the-art 32-detector, variable-resolution powder diffractometer to be installed in 1991 on the BT-1 beam hole. This instrument is being developed in cooperation with MIT.

Single crystal diffraction studies over the past year with Army and U. of Maryland scientists focussed on crystal and molecular structure determinations of high density energetic organic crystals, including large cyclic-linkaged molecules and tetranitro complexes, have revealed unusual bond angle distortions and several short intermolecular distances related to molecular stability. Work has also continued with the U. of Missouri and ORNL on the analysis of a series of polytypic structures (stacked hexagonal and cubic superlattices) associated with the martensitic transformation of sodium metal. In our applied diffraction studies of metals and ceramics, an extensive analysis with Army scientists of texture in tantalum sheet metal has revealed a "cube texture" behavior, previously observed for fcc metals, which is considered important because such texture produces anisotropic physical properties which can affect mechanical performance of projectiles an shaped-charge liners. Measurements have also continued in our neutron study (with the SAE Fatigue Design and Evaluation Committee) of residual stress distributions in test spindles for vehicles, as part of a fatigue lifetime prediction project. 
Finally, our research (with the Chalmers University of Technology) in the development and application of maximum entropy methods for biomolecular crystallography has achieved significant advances during the past year. These methods have been used to produce an electron density map of the structure of recombinant bovine chymosin, which is in remarkable agreement with the conventionally refined structure refined using isomorphous substitution. The refinement using maximum entropy procedures required a much smaller data set on the unsubstituted biomolecule and thus opens the way to a major advance in the ability to determine the phases $\underline{a b}$ initia from native protein data. In addition to these results a variety of Fourier transform techniques and newly developed methods for utilizing space group symmetry are being used to create a library of programs for crystallographic computations in the space groups in which biomolecules most commonly crystallize. In another area, a review of the Brookhaven Protein Structure Databank by our Crystal Data group has revealed that it is not uncommon in these compounds for metric symmetry to exceed the reported symmetry. Our results could have occasional important implications for protein crystallography, and we suggest that standard procedures should always include a direct determination of the metric symmetry as soon as any unit cell defining the lattice has been determined.

\title{
NIST CRYSTAL AND ELECTRON DIFFRACTION DATA CENTER
}

\author{
Alan D. Mighell and Vicky L. Himes
}

The NIST Crystal and Electron Diffraction Data Center is concerned with the collection, evaluation and dissemination of data on solid-state materials. The Data Center maintains a comprehensive database with chemical, physical and crystallographic information on all types of well-characterized substances. These materials fall into the following categories: inorganics, organics organometallics, metals, intermetallics and minerals. The data are made available to the scientific community through computer oriented modes of dissemination and through printed products. Two major databases are produced: NIST CRYSTAL DATA and the NIST/Sandia/ICDD Electron Diffraction Database. These databases are ideal for identification and characterization of solid-stated crystalline materials based on lattice/formula and dspacing/formula matching strategies. In addition, they can be used, in conjunction with new computer technologies and artificial intelligence, to build knowledge base systems for materials design and properties prediction.

During the year, work in the Data Center has focussed on the following areas: a) the development of a cross-reference program to link entries between scientific databases; b) the production of an Electron Diffraction CD-ROM, accompanying software and a users manual; c) the production of a single CD-ROM with three analytical databases (= Crystal Data, the Electron Diffraction Database, and the Powder Diffraction File); d) the development and on-line implementation of a new method for the identification of organic materials using d-spacing/\% composition matching techniques; e) the preparation of the annual update to the master database (currently over 150,000 entries; f) the preparation of 900 new entries for the Minerals Crystal Data Project; and g) the publication of a new method to identify unknown phases using electron diffraction data. 
Of particular note is the development and application of techniques to relate all crystalline compounds in a given database with those of a second database. Four types of comprehensive cross-reference files have now been generated: 1) PDF (Powder Diffraction File) versus CDF (Crystal Data File); 2) CDF versus PDF, 3) CDF versus CDF, and PDF versus PDF. The resulting files can be used for a variety of purposes (e.g., file editing materials characterization, materials design) as they allow one to establish extensive networks of materials inter-relationships or between scientific databases. These files will be distributed with our CD-ROM/PC database products that are being marketed to the scientific community.

\section{NEUTRON ACTIVATION AUTORADIOGRAPHY PROGRAM}

\section{Yu-Tarng Cheng and Jacqueline Olin}

The technique of neutron activation autoradiography to obtain images of underpainting, brushstroke, and changes in the composition of paintings has been demonstrated to be a highly valuable complement to $\mathrm{x}$-ray radiography and other techniques of painting examination. Gamma ray spectroscopy can also be conducted and provides the general composition information of the painting. It is desirable, however, to identify the specific element or elements that comprise the different features in the painting. Localized gamma ray spectroscopy has been found useful for this purpose.

An alternative method of identifying what elements are present employs changes in the film density resulting from the radioactive decay. A feasibility study was initiated by establishing a procedure that compares the local density changes in an autoradiography series to reference film responses for individual elements and combination of elements. With the anticipated increased use of image processing for the study of autoradiographs of paintings, this information can help in distinguishing areas of restoration in a painting and identifying the pigments the artist used. The locations of specific elements in a painting can be mapped and shown visually.

Grants have been received from the Samuel H. Kress Foundation and the Smithson Society to extend the present autoradiography facility to handle larger paintings and to increase the number of paintings which can be studied. New shielding will be constructed to accomodate paintings larger than $4 \mathrm{ft}$. by $4 \mathrm{ft}$. and up to $7 \mathrm{ft}$. by $8 \mathrm{ft}$. in size. In order to accomodate a larger number of paintings a second laboratory will be equipped with environmental control and security devices.

A technical study of Albert Pinkham Ryder's painting methods by autoradiography and other analytical means was completed and the results were included in the special Ryder exhibition organized by the National Museum of American Art. The exhibition is currently on a national tour. 


\section{MATERIALS MICROSTRUCTURE}

\section{SMALL ANGLE NEUTRON SCATTERING}

\section{C.J. Glinka, J.A. Gotaas, S.T. Krueger, B. Hammouda}

During the hiatus for the installation of the first complement of neutron guides, a number of modifications were made to the $8 \mathrm{~m}$ SANS instrument to adapt it for operation in the guide hall. Chief among these was the construction of a new beam shutter and associated shielding that serve to interface the instrument with the end of one of the guides (NG-5). With these modifications completed the instrument has been reassembled and operational tests and calibrations have been carried out in preparation for resuming scheduled experiments this Fall. The preliminary results from these tests indicate that while the flux at the instrument is somewhat less than at its former location close to the cold source, consistent with the expected transmission of 45 meters of neutron guide, the background levels at the SANS detector are substantially lower in the guide hall. Thus measurement conditions for experiments which have been signal-to-noise limited are now considerably improved.

In addition to the modifications that were needed for operation in the guide hall, some improvements to the $8 \mathrm{~m}$ instrument have been made as well. These include: 1) refurbishing the two-dimensional detector by replacing the anode wire plane and repurifying the counting gas mixture, 2) replacing fused silica beam windows with single crystal silicon windows to further reduce background, 3) modifying the data acquisition software to make it more user-friendly and 4) updating the user documentation for the data acquisition and analysis software. Additional major improvements to this instrument, including a new area detector, data acquisition computer and electronics, and a new velocity selector with variable wavelength resolution, are planned in the coming year as the result of funds obtained by C. Han's Polymer Blends Group in the Polymer Division. These improvements will completely modernize the instrument which will then become dedicated to research by the Polymer Blends Group for up to $75 \%$ of the available beam time.

The number and quality of the requests for SANS beam time that have been received in anticipation of resumed operation indicate that a highly interesting and productive period of SANS research is about to begin. Pending are applications of the technique to characterize the microstructure of novel nanocrystlline materials, the conformation of polymers at interfaces in microporous materials, the effects of shear on the structure of colloids and polymer blends, and the magnetic fluctuations and correlations in superconductors to name only a few. 


\section{F. Majkrzak, S. Satija, J. F. Ankner and D. A. Neumann}

A new thermal neutron reflectometer in which the incident beam can be polarized and the spin state of the reflected beam analyzed, has recently been commissioned on the BT-7 beam hole at the NBSR. In addition to obtaining reflectivity data, from which chemical and magnetic den sity profiles can be deduced, surface- or near-surface-sensitive diffracted intensities can be measured from properly oriented single crystal samples. Reflectivities down to $\sim 2$. $\times 10^{-7}$ with signal-to-noise ratios of $\sim 1$ have been measured for lamellar diblock copolymer systems. An instrumental resolution as good as $0.001 \AA^{-1}$ has been obtained with fluxes at the sample position as high as $\sim 5$. $\times 10^{5}$ neutrons $/ \mathrm{cm}^{2}$-sec. Furthermore, highly efficient, supermirror transmission polarizers make it possible to perform polarized beam grazing angle diffraction experiments on magnetic thin films such as Gd. To the best of our knowledge, this instrument is the best thermal neutron reflectometer in existence. Several examples of experiments which have recently been performed at BT-7 are described below.

Grazing-angle diffraction represents a novel application of the principles of reflectometry to the determination of in-plane structure. Using this scattering geometry, one can study surface and interfacial ordering with neutrons. We have extended our pioneering work in this field to the observation of magnetic structure using polarized neutrons. We have derived a formalism for the treatment of this scattering and have used the BT-7 instrument to perform the first measurement of this type on an epitaxial Y/Gd film. Planned improvements will include the use of a position-sensitive detector and development of a complete software package for data analysis.

Neutron reflectivity measurements continue to be performed on lamellar diblock copolymer systems. In particular, the constraints of film thickness on the morphologies of various diblock copolymers have been investigated. These studies have shown that the film thickness can cause significant alterations in the diblock copolymer structures and, consequently, perturb the molecular thermodynamics. In fact, it has been found that rather dramatic effects on the orderdisorder transition in the diblock copolymer films can occur, depending on the thickness of the films. For the thinnest films $(\sim 500 \AA)$ studied, the phase transition is broadened and shifted up in temperature by as much as $50^{\circ} \mathrm{C}$ relative to the bulk transition temperature of $150^{\circ} \mathrm{C}$.

Significant progress has also been made in the development of nonpolarizing, supermirrors which are of importance for guide coatings and other neutron optical device applications. Reflectivities of the order of $95 \%$ or better at glancing angles up to three times the critical cutoff for total reflection from an ordinary Ni surface have been measured at BT-7 for a Ni-C-Ti supermirror manufactured by the Ovonics Company of Troy, MI. Transverse scans have revealed a marked reduction in interfacial roughness in the $\mathrm{Ni}-\mathrm{C}$ - $\mathrm{Ti}$ supermirror and also in a $\mathrm{Ni}_{x} \mathrm{C}_{1-x}-\mathrm{Ti}_{y} \mathrm{Mn}_{1-y}$ supermirror manufactured by the Optoline Company of Andover, MA, when compared to earlier $\mathrm{Ni}$ - Ti prototype supermirrors. Reflectivity and diffuse scattering measurements continue to be an essential part of the ongoing program to develop improved neutron reflection coatings, which can have a revolutionary impact on the future of neutron beam research, both through development of supermirror guides and, much more efficient neutron focussing and polarizing devices. 


\title{
COLD NEUTRON PROJECT
}

\author{
G. Baltic, J. R. D. Copley, D. H. Fravel, C. J. Glinka,
} J. A. Gotaas, G. Greene, W. C. Knill,

J. G. LaRock, H. P. Layer, C. F. Majkrzak, C. O'Connor, D. Pierce, H. J. Prask, M. J. Rinehart, J. M. Rowe, S. K. Satija, I. G. Schröder, T. J. Udovic, R. E. Williams, and R. H. Williams

In June, 1989, the NBSR was shutdown to begin guide installation. As planned, the guides, fabricated by Cilas-Alcatel of France, were in-hand for the first three beam-lines (NG 5, 6, 7). The initial phase of installation entailed the very difficult job of drilling $0.50 \mathrm{~m}$ diam holes through $7.5 \mathrm{~m}$ of reinforced concrete in the reactor-building wall that had stored hot plugs. This and the placing and grouting of $0.50 \mathrm{~m}$ diam stainless steel liners were completed in August, 1989.

With technicians from Cilas-Alcatel, installation of guide segments then began. As of January 1990, the special isolation shutters and neutron guides through the reactor-building wall were in place and leak-checked. By late March, installation of the three guide segments and associated shielding from reactor-building wall to cold source was completed, along with shielding associated with the NG-0 port which ends in the reactor hall. Follow-on leak and surveillance tests of the reactor-hall confinement were completed, after which the reactor was restarted on April 8, 1990.

Following reactor startup and resumption of "thermal" neutron research, installation of the remaining sections of neutron guides NG 5-7 in the guide hall continued. It is worth noting that these initial three guides will be ${ }^{58} \mathrm{Ni}$-coated over their entire lengths to maximize intensity. Major new developments in Ni-based supermirrors will be incorporated in neutron guides NG 1,2 and 4, installation of which is planned for 1992.

Neutron instruments are being developed as quickly as possible, and are described in some detail in our Summary of Activities Report. Overall, it is planned that six instruments will be operational by early 1991. These will include an 8-m SANS to be installed and operated by the NIST Polymers Division; a diffuse scattering time-of-flight spectrometer; the $30-\mathrm{m}$ NIST/ Exxon/U. Minn. SANS, which will be among the world's best in resolution, intensity, and versatility; the cold neutron depth-profiling facility; the new cold neutron prompt-gamma activation analysis station, which is expected to be the world's best full-time instrument of this type; and the neutron-lifetime experiment which will be installed at the fundamental neutron physics station.

The CNRF, which is a response to a critical national need for a cold neutron measurement capability, will be a National User Facility; to this end, the experimental stations installed will be available to the scientific and engineering community on the basis of scientific merit of proposals or in Participating Research Teams. A Program Advisory Committee (PAC) will play a critical role in advising NIST on the utilization of the facility. 
On October 24, 1989, the PAC for the CNRF met for its first session. The PAC members are Chairman S. K. Sinha, Brookhaven National Laboratory and Exxon Research and Development Corp.; D. L. Price, Argonne National Laboratory; E. A. Schweikert, Texas A\&M University; and $\mathrm{H}$. Yu, University of Wisconsin. In the first meeting the committee made the following principal recommendations:

- Utilize calendar 1990 for "shake-down" and development.

- $\quad$ Send out the first call for proposals toward the end of 1990, with two (possibly three) submission periods a year thereafter.

- $\quad$ Have several external reviewers evaluate the proposals by mail with the PAC allotting instrument time based on the reviews.

- $\quad$ Expand the PAC.

- $\quad$ Form a CNRF User Committee in 1990.

Action is being taken to develop the details of all aspects of the user program with the recommendations of the PAC as the starting framework. Bill Kamitakahara, who is newly added to the staff, will be the scientific coordinator for the program.

Relating to instrument development, the following major collaborations have been initiated in this period. The University of Minnesota has agreed to participate in the development and use of two high resolution instruments: the 30-m NIST/Exxon/U. Minn. SANS and the cold neutron reflectometer. Their utilization is expected to focus on the elucidation of the structure and microstructure of polymers and other materials as well as surface and interfacial structure and interactions. According to the agreement, the University of Minnesota will provide a share of the development costs of the instruments, and will continue contributions to maintain state-of-theart capabilities following instrument installation. IBM, through its Almaden Research Center, has entered into a similar agreement for development and utilization of the cold neutron reflectometer. Their interests are also expected to focus on polymers and surface interactions.

In March, the second issue of our newsletter, the Neutron Standard, was sent to approximately 2500 scientists and engineers. This issue highlighted the installation of the guides and the development of the instruments. In the next issue we will include a detailed description of instruments and a request for proposals.

Detailed planning for a workshop on condensed matter spectroscopy with cold neutrons, tentatively scheduled for mid-1991, has begun. 


\section{INDEPENDENT PROGRAMS}

The three major independent (non-collaborative) NIST programs using the reactor are: 1) Nuclear Methods Group in the Center for Analytical Chemistry, 2) Standard Neutron Fields for Neutron Flux Calibration and Materials Dosimetry in the Center for Radiation Research, and 3) the Fundamental Physics and Quantum Metrology Program of the Center for Atomic, Molecular and Optical Physics. Overviews of these programs are presented here. The major non-NIST independent programs were summarized in the RRD Annual Report.

\section{NUCLEAR METHODS GROUP}

\section{R. R. Greenberg \\ Center for Analytical Chemistry}

The development and application of nuclear analytical techniques for greater accuracy, higher sensitivity and better selectivity are the goals of the Nuclear Methods Group. A high level of competence has been developed in both instrumental and radiochemical neutron activation analysis (INAA and RNAA). In addition, the group has the capability of using neutron beams as analytical probes for both prompt gamma activation analysis (PGAA) and neutron depth profiling (NDP). NDP determines concentrations of several important elements (isotopes) versus depth profiles within the first few micrometers of a surface by energy analysis of the prompt charged-particles emitted during neutron bombardment. PGAA, on the other hand, measures the total amount of an analyte present throughout a sample by the analysis of the prompt gamma-rays emitted during neutron capture. These techniques (INAA, RNAA, PGAA and NDP) provide a powerful combination of complementary tools to address a wide variety of analytical problems of great importance in science and technology.

The use of a variety of nuclear methods has continued to contribute to the Standard Reference Material (SRM) certification effort; this year's efforts include multielement determinations performed on a number of SRMs including: Total Diet, Frozen Mussel Tissue, Apple Leaves, Peach Leaves, Bone Ash, Bone Meal, Water, Boron in Silicon, two Wear Metals in Oils, and three Soils. Group members are serving as Technical Champions for several of these new SRMs, and as such are responsible for scientific decisions made throughout the production and certification processes of these materials. In collaboration with members from other groups in the Inorganic Analytical Research Division, a dissolution study of the two new leaf materials has been completed which identifies problems potentially leading to analytical errors during the certification analyses. In addition, a study to determine the feasibility of preparing a dietary slurry SRM, instead of the traditional type of dried material, is under investigation. Members of the Nuclear Methods Group have also collaborated with researchers from the Microanalysis Group (553) in developing a boron depth-profiling SRM.

Recent applications of NAA in the life sciences by the Group include non-classical detection and determination of tags associated with biological macromolecules such as proteins, enzymes and antibodies. In one application, an activatable tag has been attached to an antibody used in a medical diagnostic test. The INAA determination of the activatable tag is then used as the detection step of the diagnostic analysis. Research is continuing on the polyacrylamide gel 
electrophoresis neutron activation analysis technique (PAGE-NAA). The activation and subsequent determination of phosphorus in phosphoproteins has already been demonstrated, and research in this area was included as part of the $\mathrm{Ph}$. D. requirements for one group member who has received her doctorate this past year. Research to extend this technique to the determination of other elements in specific macromolecules is underway. Such advanced uses of NAA in the life sciences may open a wide variety of applications for nuclear analytical chemistry.

The Biomonitoring Specimen Bank Research Project has continued its research support for other agencies' monitoring programs. These programs include the EPA human liver project, the NOAA National Status and Trends (NS\&T) program, the NCI Micronutrient program, the IAEA/NIST/FDA/USDA Total Diet Study, the NOAA Alaska Marine Mammal Project, and the National Marine Mammal Tissue Bank. Research has centered on specimen banking protocols and improved analytical methodology. The Group's participation in intercalibration exercises with the project participants and the development of QA materials for various marine analyses has helped to enhance the quality of the analytical results used in the assessment of the environmental health of the nation.

The joint NIST/FDA/USDA study of trace elements in human diet, sponsored by the International Atomic Energy Agency, has completed its sixth year. A total of 200 diets from different countries have been analyzed to date for minor and trace elements. The data obtained from the U. S. diet composites have confirmed daily intake results for some of the elements investigated by the FDA (based on individual food analysis), as well as established reliable daily dietary intakes for additional elements including $\mathrm{B}, \mathrm{Cr}, \mathrm{Cs}, \mathrm{Li}$ and $\mathrm{Sn}$. In the case of $\mathrm{Li}$, the observed intake values are considerably lower than earlier published results.

The collaboration with Brian Clarke of McMaster University on neutron activation-mass spectrometry has continued to provide valuable information on ultratrace levels of boron and lithium. A wide variety of materials was investigated this past year, and results were obtained for boron and lithium concentrations in several different protein components in blood, various individual foods, and a number of geological reference materials.

The Group has taken an active role in the NIST program on high-temperature superconductivity research, both in the measurement of impurities in starting materials and final products, and in determination of the stoichiometry of metallic constituents. The effort this year has centered on the development of accurate, rapid measurements of these materials by both NAA and PGAA. An effort to establish an accurate, monitor activation analysis technique for further study of high temperature superconductors at NIST is underway.

Nearly a decade ago, a systematic error for PGAA was observed in which elemental sensitivities (counts $/ \mu \mathrm{g}-\mathrm{s}$ ) increased with increasing hydrogen concentration. Sensitivities in hydrogenous samples have been observed to increase by up to approximately $25 \%$ relative to samples with little $\mathrm{H}$. Until now, this error has been handled by matching $\mathrm{H}$ concentrations in samples and standards without fundamental understanding of the problem. Substantial progress has recently been made in understanding the causes of this sensitivity enhancement, and in developing a method of analysis in which these effects are eliminated. Theoretical and experimental studies have shown that the elemental sensitivities in PGAA depend upon the scattering density (or 
hydrogen concentration), as well as the sample shape. Recent work has demonstrated that for spherical samples, neutron scattering only serves to mitigate the effects of neutron self shielding, and produces no additional enhancement.

Research on the recoil-nucleus time-of-flight NDP technique has focused on the problem of detecting (with good energy resolution) the low energy heavy nuclei which are emitted along with the light nuclei used in conventional NDP. These heavy nuclei can be used to provide very high resolution depth profiling capabilities in the sample region very close to the surface. Initial measurements appear to have validated this approach, and efforts are underway to determine how closely the actual depth resolution measured approaches the calculated values.

During the past year, a large part of the Group's efforts has been directed at the exploitation of the analytical applications of cold neutrons. These efforts are needed to take full advantage of the guided cold-neutron beams soon to be available at the new Cold Neutron Research Facility (CNRF). The Group's involvement includes the design and construction of state-of-the-art instruments for both PGAA and NDP using cold neutrons. A new chamber for the cold neutron depth profiling (CNDP) instrument has been installed at the NIST Cold Tube West (CTW) location, and the new facility will be the closest instrument to the reactor cold source. The 60$\mathrm{cm}$ diameter chamber has ultra-high vacuum capability, and has been designed to be adaptable to many different types of experiments. The final configuration will allow remote scanning of $15 \times 15 \mathrm{~cm}$ samples, and will also allow rotation of both sample and detector angles relative to the beam.

The cold neutron prompt gamma activation analysis (CNPGAA) instrument is currently under construction and will be ready for measurements this fall. Over the past year, several new mechanically-strong, radiation-stable, synthetic glasses containing Li- 6 have been developed to efficiently absorb neutrons with minimal gamma-ray emission. These glasses will be used in the beam shutter and in the sample chamber. The conceptual design of the beam line is now complete, and it will include a cold beryllium/bismuth filter to make this the finest facility in the world for PGAA. In addition to greatly enhancing the sensitivities for all elements compared to existing thermal neutron PGAA instruments, collaborative measurements with Jülich have indicated that the cold neutron facility should allow the determination of a few micrograms of hydrogen in a wide variety of materials.

A long-range program to explore and develop the analytical applications of focused beams of cold neutrons has been initiated within the Group. The ultimate goal of this research is to produce beams of neutrons which have intensities several orders of magnitude greater than previously available. Such beams will greatly enhance the capabilities of both PGAA and NDP, and may ultimately lead to a neutron probe for microanalysis. The neutron microguide appears to be the most promising approach to achieve analytically useful focused neutrons. As a first approach, a device will be developed and tested using a stack of ultrathin, nickel-coated single-crystal silicon wafers as focusing elements. The silicon wafers act as the transmission medium for the neutrons, which reflect from the $1000 \AA$ A nickel surface coatings. The superposition of the individual outputs becomes the focal point. One hundred of these wafers have been obtained for tests of this first focusing element. Ultimately, this focusing element will be combined with a real-time, high-resolution neutron imaging detector to measure the neutron distribution and intensity. 
The strong interaction with industrial scientists using NDP, PGAA, and NAA has continued during the year with a growing number of guest workers, research associates, and joint publications. In collaboration with researchers at Eastman Kodak, NDP has been used to identify unambiguously, and to quantify the surface boron on "as received" single crystal silicon wafers. NDP requires no special sample preparation prior to analysis, in contrast to commonly used analytical techniques. By carefully controlling a variety of sample processing procedures prior to NDP analysis, the source of boron has been identified as ambient atmospheric boron compounds which react with the exposed surface of the silicon wafer and become incorporated into the native oxide layer.

The Nuclear Methods Group is also collaborating with scientists from the NIST Center for Atomic Molecular and Optical Physics, the NIST Center for Radiation Research, and the University of Sussex in a new measurement of the neutron lifetime. The technique used involves detecting the protons which decay in a neutron beam passing through a superconducting-magnet proton trap. A measurement of the neutron lifetime has been made with a cold-neutron beam at the Institut Laue-Langevin in Grenoble (France). A value of $893.6 \pm 5.3 \mathrm{~s}$ was determined, and this has been reported in a paper in Physical Review Letters. Additional measurements will be made at the new NIST CNRF later this year.

During the coming year the Group will continue to improve the accuracy, sensitivity and productivity of nuclear methods as applied to elemental measurements. Problems to be addressed include those inherent in sample preparation, irradiation, radiochemical separation, counting and data reduction, with the goal of minimizing and quantifying various sources of random and systematic errors in analysis by nuclear methods. Maintaining full accuracy at high count rates using current generation data acquisition electronics is the goal of our count rate dependent studies. Accurate quantification of gamma-ray self-absorption and measurement of the shape of the efficiency curve are required for accuracy in monitor activation analysis (since matching of sample with primary standards is not done). The development of monitor activation analysis is part of the high temperature superconductivity effort to achieve rapid sample turnaround with minimum sacrifice of accuracy; however, the approach also provides good quality control when used in parallel with traditional primary standard NAA.

\section{NEUTRON INTERACTIONS AND DOSIMETRY GROUP}

\section{J. A. Grundl (Ionizing Radiation Division)}

The Neutron Interactions and Dosimetry Group develops and applies well-characterized neutron fields and related capabilities for neutron dosimetry methods evaluation and standardization, for detector development and calibration, and for reactor cross-section measurements. Involvement with outside organizations, both in the federal and private sectors includes many types of research and technology assistance programs as well as leadership roles on national and international standards and radiation policy making bodies. 
A selection of accomplishments for FY-90 with emphasis on NIST reactor related activities are outlined below in titled paragraphs grouped under four projects.

\section{DOSIMETRY FOR MATERIAL PERFORMANCE ASSESSMENT}

This project provides some form of measurement assurance, standardization, or methods development for nearly every approach to materials dosimetry employed in the United States.

NIST/Nuclear Regulatory Commission (NRC) Contract. By law, Title 10 of the Code of Federal Regulations, Appendix $\mathrm{G}$ and $\mathrm{H}$ require that a program, involving irradiation of metallurgy test specimens and dosimeters, be carried out for the surveillance of pressure vessel embrittlement damage. NIST continues to participate in its Pressure Vessel Surveillance Dosimetry Contract with the NRC to benchmark reference dosimetry measurements and calculations and continues as general dosimetry consultant to the NRC.

NRC Regulatory Guide Preparation. Major involvement continues in the development of a draft regulatory guide "Status of a New Regulatory Guide on Methods and Assumptions for Determining Pressure Vessel Fluence," to provide guidance for improving and benchmarking neutron transport calculations.

ASTM Benchmark Standard. A draft of this ASTM Standard Guide for Benchmark Referencing of Neutron Dosimetry for Reactor Pressure Vessel Surveillance was re-submitted by NIST to ASTM in preparation for an E10.05 ballot at ASTM and Radiation Effects Symposium meeting in Nashville with the intent of another review at the January 1991 San Diego ASTM meeting.

NIST/Westinghouse Cooperative Agreement. Dosimetry Measurement Assurance Program: Measurement assurance activities for Westinghouse radiometric (activation foil) and Solid State Track Recorder (SSTR) dosimetry continues. NIST is especially interested in problems associated with obtaining reliable masses for SSTR fissionable deposits in the nano-gram to picogram range. Cooperative Research on New Dosimeter: A new neutron dosimeter has been conceived and tested. The dosimeter consists of a fissile layer placed adjacent to a polymer material that becomes conducting as a result of implantation of energetic heavy ions such as those from neutron-induced fission.

Dosimetry Methods Development for Reactor Support Structures. Dosimetry for Support Structures in Operating Power Reactors: An NRC priority effort in the Heavy Section Steel Technology (HSST) Program is evaluation of implications of low-temperature, low-fluence-rate embrittlement on reactor vessel support structures. The materials-damage interests associated with these effects are in reactor support structures which have this kind of spectral environment but have not been of concern in the past because of their low exposure to fast neutrons. NIST is responsible for consultation and contracting for the dosimetry measurements, and for benchmarking the measurements against NIST standard neutron fields.

Dosimetry Development for Test Reactors Metallurgy Irradiations. NIST has assumed a dosimetry consultants role for the new, combined Materials Engineering Associates and Oak Ridge National Laboratory run Heavy Section Steel Technology (HSST) Program at the University of Michigan Research Reactor. The NIST responsibility, in addition to providing an 
NRC technical contact for dosimetry and general reactor irradiations issues, is to insure that preirradiation experimental dosimetry is done before long (several years) irradiations get underway.

Energy Response of Innovative Electronic-Hardware Dosimetry. The Nuclear Effects Directorate (NED) at the Aberdeen Proving Ground has been evaluating a new personnel dosimetry system for battlefield use by the Army. Special NIST neutron-field facilities were used to establish the neutron energy sensitivity of this semiconductor device. Multiple irradiations were performed for NED in a thermal neutron beam, in the $2-\mathrm{keV}$ scandium filtered beam, in the $24-\mathrm{keV}$ iron filtered beam, and at the 144-kev silicon filtered beam, all at the NIST Reactor, and at several Van de Graaff beams, and finally at the NIST ${ }^{252} \mathrm{Cf}$ source.

7LiF Gamma Dosimeter for Oconee Reactor Cavity Dosimetry. The results of a test of "LiF Chips" as gamma dosimeters in the cavity surrounding a reactor pressure were analyzed and reported. The results appear to contradict previously reported neutron sensitivity data and suggest that the dosimeter package may be better than expected as a gamma monitor for mixed gamma and neutron radiation fields.

\section{PERSONNEL DOSIMETRY}

Standard neutron fields are used to calibrate radiation protection instrumentation and to investigate and test new types of dose measuring techniques. Responsibility in national and international dosimetry methods research focuses on tissue dose modeling, and tissue equivalent proportional counter (TEPC) measurements, and the development of written standards.

Characterization of Neutron Exposure Fields. As a result of TEPC measurements, the Armed forces Radiobiology Research Institute (AFRRI) recently obtained very surprising results in experiments which examined the relative biological efficiency (RBE) for lethality in mice exposed to reactor radiations. In brief, the experiments indicated that a slight $(5 \%)$ addition of neutron dose, into a pure gamma-ray field, decreased the lethal dose for the mice by almost $40 \%$. The neutron and gamma-ray dose components were determined by conventional AFRRI ion chamber dosimetry. However, from TEPC and fission chamber measurements made this year, it now appears that the neutron kermas measured with ionization chambers are too low. In the most extreme case the neutron kerma inferred from both TEPC and fission chamber measurements is seven to nine times greater than that measured with ionization chambers. The larger neutron doses combined with the observed lethality of mice imply a neutron RBE fairly constant with neutron energy, as expected.

Summary of Threshold Neutron Detector Measurements at AFRRI. A summary of threshold neutron detector chamber measurements made over a period of about 6 years is complete. In addition to discussion of measurements in two of AFRRI's conventional fields, the summary documents measurements with a ${ }^{237} \mathrm{~Np}$ fission chamber, which is now used as a neutron monitor in AFRRI exposure rooms.

Instrument Calibration Service. Approximately 40 neutron radiation protection instruments were calibrated this year. As usual, the majority of the calibrations were done for commercial nuclear power plants, but our customers also included institutions as diverse as Redstone Arsenal and Baylor College of Medicine. 
Performance Tests of "Bubble Dosimeters". We are continuing our measurements of the properties of "bubble", or superheated drop, neutron detectors. In collaboration with J. B. Hunt of the National Physical Laboratory (NPL), we have concluded a major study of linearity, and response as a function of neutron energy, for several of these devices. Most of the data were taken at NPL, with additional low-energy data points taken at the NIST Reactor filtered beams. The results of this study are to be published in Radiation Protection Dosimetry, under the title, "Measurement of the Energy Response of Superheated Drop Neutron Detectors".

ICRU Publication on Practical Determination of Dose Equivalents. Our report committee is preparing the ICRU report on the practical use of certain important quantities; i.e., instrument design, calibration techniques, etc. Our report, entitled "Measurement of Dose Equivalents from External Photon and Electron Radiations", has been completed and submitted to the main ICRU commission for its approval.

ISO Document on Instrument Calibration. The (it-is-hoped) final version of ISO document CD 10647, "Procedures for Calibrating and Determining the Energy Response of Neutron Measuring Devices Used for Radiation Protection", has been submitted to the ISO secretariat, and from there gone to the member organizations (e.g., ANSI, for the US) for voting.

Data Acquisition System for AFRRI Dosimetry Group. NIST has provided a PC-based data acquisition system and software to replace the two HP-85 systems previously used for Ionization Chamber and Fission Chamber data acquisition by the Armed Forces Radiobiology Research Institute Dosimetry Group.

\section{RESEARCH AND TECHNOLOGY}

Research and technology assistance are strongly coupled in neutron dosimetry. A multiplicity of institutional involvements, drawn to the group by the availability of unique irradiation facilities and measurement capabilities, encourages a variety of attractive projects and unavoidable responsibilities.

Neutron Lifetime - Absolute Neutron Counting. The result of the first phase of the Univ. of Sussex/NIST/Geel collaboration to measure the free neutron lifetime was reported in Phys. Rev. Letters. The goal for this first phase of the project, as stated in our proposal to the DoE, was to achieve an overall uncertainty of $\pm 0.5 \%$ at this juncture; and the reported value of 893.6 $\pm 5.3 \mathrm{~s}$ comes very close to this goal. The NIST alpha-gamma coincidence apparatus has been tested with an isotopic alpha-gamma source and is ready for neutron beam runs as soon as a beam is available.

Benchmark Measurements for Criticality Counting. Two series of careful measurements of neutron leakage from a water-moderated Cf- 252 source have been completed and compared with rigorous Monte Carlo calculations performed by the Computational Methods Development Group at Los Alamos Scientific Laboratory.

Neutron Fluence Rate Measurements at CNRF Guide Positions. Several measurements of both fast and thermal neutron fluence rates were made at various positions on cold neutron guide 
NG6. All of these measurements were made at a time when the cold source was not operational and filled with warm helium gas rather than heavy water ice.

Collaboration with U. S. Naval Academy. Monte Carlo calculations with the MCNP code have been made at NIST to determine the neutron spectrum from a $14-\mathrm{MeV}$ neutron generator at the U. S. Naval Academy (USNA). Comparisons of dose equivalent with similar calculations by USNA showed a significant (40\%) discrepancy. Further investigations revealed that the MCNP code at USNA did not duplicate sample problems distributed with the computer code package.

Collaboration with Institut de Protection et de Surete Nucleaire (IPSN). Because of our experience in calculations of anisotropic emission from small neutron sources NIST was asked to make calculations for a source used by IPSN. Also, we were asked to check their calculations of neutron spectra from a $14-\mathrm{MeV}$ neutron source moderated by iron, uranium-238, and heavy water.

Neutron Penetration in Slabs of Finite Extent. Monte Carlo calculations of neutron transmission through slabs have been performed to help the U.S. Navy estimate shielding of personnel on submarines carrying nuclear missiles. These calculations demonstrate that neutron and gammaray penetration is insensitive to the position of a slab between a localized (point) source and detector. Furthermore, an angular parameter can be specified such that the relative contribution of neutrons or photons within that angle is also insensitive to the slab position.

Radiation Shielding Calculations for the NIST Cold Neutron Facility (CNRF). Calculations of the necessary shielding for two shutters at the CNRF and for shielding around neutron guides were made. The latter calculations approximated the neutrons scattered from the walls of a guide as a line source. All calculations predicted dose equivalent rates which were conservative as determined by measurements with shielding in place.

\section{IRRADIATION AND CALIBRATION FACILITIES}

Neutron Source Strength Calibrations in FY-90. Fifteen neutron source-strength calibrations were accomplished this year by the $\mathrm{MnSO}_{4}$ Bath Technique.

Fission Neutron Irradiations Operations. The storage cave for radioactive sources, and standard neutron field assembly pieces is essentially complete. The extensive heavy-work required to build this facility was carried out entirely with staff personnel.

\section{FUNDAMENTAL NEUTRON PHYSICS}

\section{G. L. Greene (Quantum Metrology Division)}

Two instrumental positions at the CNRF have been designated as experimental stations for investigations in an area of research which has come to be known as "Fundamental Neutron Physics." This work includes measurements of basic neutron properties, tests of fundamental symmetries of nature as well as investigations involving advanced methods in neutron optics. An additional program in advanced methods for neutron flux determination will have implications 
in neutron dosimetry, analytical chemistry, and nuclear physics. One instrumental position (on NG-7) will be on a monochromated beam, devoted to neutron interferometry. The other position (on NG-6) will be a full flux end position. It will initially be devoted to studies of weak interaction physics.

Design and construction work on the neutron interferometer position has been focussed primarily on the implementation of a sophisticated seismic and vibrational isolation system. Neutron interferometers are exceptionally sensitive to external noise sources. The seismic isolation will consist of a cascaded series of passive isolation elements which will allow the use of an entirely new class of neutron interferometers employing separated perfect crystals as optical elements. This work is a collaboration with the University of Missouri, the University of Vienna (Austria), and the University of Melbourne (Australia).

The end position will initially be employed for an experiment to determine the neutron lifetime. This quantity has important implications for the study of the theory of weak interactions, for astrophysics and cosmology. The neutron life apparatus has already been used in a initial measurement at the Institut Laue Langevin in Grenoble. It will be installed at NG-6 in October 1990. This work is a collaboration between NIST, the University of Sussex (England), the Central Bureau for Nuclear Measurements (Belgium), and the Scottish Universities Research Reactor. It is supported in part by the Department of Energy and the Science and Engineering Research Council (U.K.). 


\section{Outputs/Interactions}




\section{PUBLICATIONS: Reactor Radiation Division}

Anastasiadis, S. H.; Russell, T. P.; Satija, S. K.; Majkrzak, C. F, "The Morphology of Symmetric Diblock Copolymers as Revealed by Neutron Reflectivity," J. Chem. Phys. 92, 5677 (1990).

Anderson, I. S.; Berk, N. F.; Rush, J. J.; Udovic, T. J.; Barnes, R. G.; Richter, D.; Magerl, A., "Rapid Low Temperature 'Hopping' of Hydrogen in a Pure Metal: The $\mathrm{ScH}_{x}$ System," Phys. Rev. Lett. $\underline{65}, 1439$ (1990).

Ammon, H.; Choi, L.; Damvarapu, C. S.; Iyer, R. S.; Alster, S., "Stucture of Cubane-1, 4diammonium Bis-(trinitromethide)," Acta Crystallogr. C 46, 295 (1990).

Ankner, J. F.; Zabel, H.; Neumann, D. A.; Majkrzak, C. F.; Matheny, A.; Dura, J. A.; Flynn. C. P., "Neutron Reflectivity Study of Gd-Y Interface," in Neutron Scattering for Material Science, edited by S. M. Shapiro, S. C. Moss and J. D. Jorgensen, Mater. Res. Soc. Symp. Proc., Vol. 166 (Materials Research Society, Pittsburgh, 1990), p. 109.

Ankner, J. F.; Zabel, H.; Neumann, D. A.; Majkrzak, C. F.; Dura, J. A.; Flynn, C. P., "GrazingAngle Neutron Diffraction," J. Phys. (Paris) 므, C7-189 (1989).

Bashir-Hashemi, A.; Ammon, H. L.; Choi, C. S., "Chemistry and Structure of Phenylcubanes," J. Org. Chem. 55, 416 (1990).

Baur, W. H.; Bieniok, A.; Shaaon, R. D.; Prince, E., "Neutron Powder Diffraction Study and Thermogravimetry of Sodium Cesium Zeolite Rho," Z. Kristallogr. 187, 253 (1989).

Beach, R. S.; Borchers, J.; Salamon, M. B.; Du, R.; Flynn, C. P., "Observation of Intermediate Spin States in Er/Y Superlattices," J. Appl. Phys. $\underline{67}, 5710$ (1990).

Berk, N. F.; Glinka, C. J.; Haller, W.; Sander, L. C., "Analysis of SANS from Controlled Pore Glasses" in Neutron Scattering for Materials Science, edited by S. M. Shapiro, S. C. Moss, J. D. Jorgensen, Mater. Res. Soc. Symp. Proc., Vol. 166 (Materials Research Society, Pittsburgh, 1990), p. 409.

Berk, N. F.; Rush, J. J.; Udovic, T. J.; Anderson, I. S., "Anomalous Hydrogen Dynamics in Rare Earth Metals," J. Less-Common Met. (in press).

Biswas, R.; Bouchard, A. M.; Kamitakahara, W. A.; Grest, G. S.; Soukoulis, C. M., "Vibrational Localization and Vibrational Spectra in Amorphous Silicon," in Atomic Scale Calculations in Materials Science, edited by J. Tersoff, D. Vanderbilt, and V. Vitek, Mater. Res. Soc. Symp. Proc., Vol. 141 (Materials Research Society, Pittsburgh, 1989), p. 213.

Boolchand, P.; Enzweiler, R. N.; Cappelletti, R. L.; Kamitakahara, W. A.; Cai, Y.; Thorpe, M. F., "Vibrational Thresholds in Covalent Networks," Solid State Ionics $\underline{39}, 81$ (1990).

Bowman, R. C.; Maeland, A. J.; Venturini, E. L.; Rush, J. J.; Cantrell, J. S., "Studies of the Structure and Properties of Amorphous a- $\mathrm{Zr}_{76} \mathrm{Fe}_{24} \mathrm{H}_{x}, " \mathrm{Z}$. Phys. Chem. $\underline{163}, 373$ (1989). 
Bowman, R. C.; Torgeson, D. R.; Barnes, R. G.; Maeland, A. J.; Rush, J. J., "Relationship of Hydrogen Site Occupancy to Diffusion Behavior in Crystalline and Amorphous $\mathrm{Zr}_{2} \mathrm{PdH}_{x}$, Z. Phys. Chem. 163, 203 (1989).

Bradford, D.; Hammouda, B.; Bubeck, R. A.; Schroeder, J. R.; Glinka, C. J.; Thiyagarajan, P., "Deformations of Polystyrene Chains Upon Hot Stretching," J. Appl. Crystallogr. 23, 1 (1990).

Carstanjen, H.-D.; Huang, X. Y.; Kieninger, W.; Kirchheim, R.; Rush, J. J.; Udovic, T. J.; Glinka, C., "A Neutron Scattering Study of Deuterium Trapping by Dislocations," Z. Phys. Chem. Neue Folge 163, 203 (1989).

Cava, R. J.; Marezio, M.; Krajewski, J. J.; Peck, W. F.; Santoro, A.; Beech, F., "Neutron Powder Diffraction Study of $\mathrm{Pb}_{2} \mathrm{Sr}_{2} \mathrm{YCu}_{3} \mathrm{O}_{8}$, the Prototype of a New Family of Superconductors, "Physica C 157,272 (1989).

Cava, R. J.; Santoro, A.; Krajewski, J. J.; Fleming, R. M.; Waszczak, J. V.; Peck, W. F.; Marsh, P., "The Crystal Structure of the $60 \mathrm{~K}$ Superconductor $\mathrm{La}_{1.6} \mathrm{Sr}_{0.4} \mathrm{CaCu}_{2} \mathrm{O}_{6 \pm d}$," Physica $\mathrm{C}$ (in press).

Casella, R. C., "Nonlocal phase shifts induced by static electric fields in neutron interferometers when the path enclosed charge vanishes", Phys. Rev. Lett. (in press).

Casella, R. C., "Comparison of Interplanar-Boson-Exchange Models of High-Temperature Superconductivity--Possible Experimental Tests," Appl. Phys. Lett. 55 (9), 908 (1989).

Chaiken, A.; Dresselhaus, M. S.; Orlando, T. P.; Dresselhaus, G.; Tedrow, P. M., Neumann, D. A.; Kamitakahara, W. A., "Anisotropic Superconductivity in $\mathrm{C}_{4} \mathrm{KHg}$," Phys. Rev. B 41,71 (1990).

Choi, C. S.; Prask, H. J.; Ostertag, C. P., "Texture Study of Magnetically Aligned $\mathrm{YBa}_{2} \mathrm{Cu}_{3} \mathrm{O}_{7}-$ Type Materials by Neutron Diffraction," J. Appl. Crystallogr. 22, 465 (1989).

Cieplak, M. Z.; Xiao, G.; Chien, C. L., Stalick, J. K.; Rhyne, J. J., "Unexpected Effects of Gold on the Structure, Superconductivity, and Normal-State of $\mathrm{YBa}_{2} \mathrm{Cu}_{3} \mathrm{O}_{7}$," Appl. Phys. Lett. $\underline{57}, 934$ (1990).

Cieplak, M. Z.; Xiao, G.; Bakhshai, A.; Artymowicz, D.; Bryden, W.; Chien, C. L.; Stalick, J. K.; Rhyne, J. J., "Incorporation of Gold into YBa Cu O: Structure and T Enhancement," Phys. Rev. $\mathrm{B}$ (in press).

Clinton, T. W.; Lynn, J. W., "Magnetic Ordering of Er in Powder and Single Crystals of $\mathrm{ErBa}_{2} \mathrm{Cu}_{3} \mathrm{O}_{7}$," Physica C (in press).

Collins, D. M.; Prince, E., "Exponential Density: Exact Fitting of Structure Moduli by Entropy Maximization," Proc. of the International School on Crystallogr. Computing, (in press).

Copley, J. R. D., "The Effects of Chopper Jitter on the Time-Dependent Intensity Transmitted by Multiple-Slot Multiple Disk Chopper Systems," in Advanced Neutron Sources 1988, edited by D. K. Hyer, The Inst. Phys. Conf. Series, Vol. 97 (Institute of Physics, Bristol and New York, 1989), p. $327-339$.

Copley, J. R. D.; Mildner, D. F. R., "Production of Intense Clean Neutron Beams for Neutron Absorption Experiments," Trans. Am. Nucl. Soc. 61, 105 (1990). 
Copley, J. R. D., "An Analytical Method to Characterize the Performance of Multiple Section StraightSided Neutron Guide Systems," Nucl. Instrum. \& Methods in Phys. Res. A 287, 363-373 (1990).

Copley, J. R. D., "On the Use of Acceptance Diagrams to Calculate the Performance of Multiple Section Straight-Sided Neutron Guide Systems" in Advanced Neutron Sources 1988, edited by D. K. Hyer, The Inst. Phys. Conf. Series, Vol. 97 (Inst. of Physics, Bristol and New York, 1989), p. 821- 828.

Copley, J. R. D., "Acceptance Diagram Analysis of the Performance of Vertically Curved Neutron Monochromators," Nucl. Instrum. \& Methods in Phys. Res. A (in press).

Copley, J. R. D., "Optimized Design of the Chopper Disks and the Neutron Guide in a Disk Chopper Neutron Time-of-Flight Spectrometer," Nuclear Instruments \& Methods in Phys. Res. A 291, 519-532 (1990).

Erwin, R. W., "Domain Size and Spin Waves in a Rentrant Spin Glass," J. Appl. Phys. 67, 5229 (1990).

Erwin, R. W.; Rhyne, J. J.; Borchers, J. A.; Salamon, M. B.; Du, R.; Flynn, C. P., "Magnetoelasticity in Rare-Earth Multilayers and Films," in Neutron Scattering for Material Science, edited by S. M. Shapiro, S. C. Moss, J. D. Jorgensen, Mater. Res. Soc. Symp. Proc., Vol. 166, (Materials Research Society, Pittsburgh, 1990), p. 133.

Erwin, R.; Rhyne, J. J.; Borchers, J.; Du, R.; Salamon, M.; Flynn, C. P., "Magnetoelasticity in RareEarth Superlattices and Films," Physica B $\underline{159}, 111$ (1989).

Fan, Y.; Neumann, D. A.; Solin, S. A.; Kim, H. Pinnavaia, T.J., "Elastic and Inelastic Neutron Scattering Study of Hydrogenated and Deuterated Trimethylammonium Pillared Vermiculite Clays," J. Chem. Phys. (in press).

Felcher, G.P.; Schneider, D.; Farnoux, B.; Majkrzak, C.; Spooner, S.; Timmins, P.; White J.; Wignall, G., "Small-Angle Scattering and Reflectometry," in Proceedings of the Oak Ridge National Laboratory/ Brookhaven National Laboratory Workshop on Neutron Scattering Instrumentation at High-Flux Reactors, Report CONF-8906311, (1990), p. 39-47.

Fernandez-Baca, J. A.; Nicklow, R. M.; Tun, Z.; Rhyne, J. J., "Magnetic Excitations in Thulium Metals," J. Appl. Phys. 67, 5283 (1990).

Fernandez-Baca, J. A.; Hennion, M.; Hennion, B.; Rhyne, J. J.; Fish, G. E., "Spin Dynamics of Amorphous $\mathrm{Fe}_{90-x} \mathrm{Ni}_{x} \mathrm{Zr}_{10}$," J. Appl. Phys. 67, 5223 (1990).

Fischer, R.; Baur, W.; Shannon, R.; Parise, J.; Faber, J.; Prince, E., "New, Different Forms of Ammonium Loaded, and Partly Deammoniated Zeolite Rho Studied by Neutron Powder Diffraction," Acta Crystallogr. C $\underline{45}, 983$ (1989).

Forano, C.; Slade, R. C.; Krogh, E.; Andersen, I. G.; Prince, E., "Neutron Diffraction Determination of Full Structures of Anhydrous Li-X and Li-Y Zeolytes," J. Solid State Chem. 82, 95 (1989).

Giebultowicz, T. M.; Klosowski, P.; Rhyne, J. J.; Udovic, T. J.; Furdyna, J. K.; and Giriat, W., "Magnetic Exchange Interactions in Co-Based II-VI Diluted Magnetic Semiconductors: $\mathrm{Zn}_{1-}$ ${ }_{x} \mathrm{Co}_{x} \mathrm{~S}$," Phys. Rev. B 41,504 (1990). 
Giebultowicz, T. M.; Klosowski, P.; Rhyne, J. J.; Samarth, N.; Luo, H.; Furdyna, J. K., "Neutron Diffraction Studies of $\mathrm{Cd}_{1-x} \mathrm{Mn}_{x}$ Se Epilayers and ZSe/MnSe Multilayers," in Neutron Scattering for Material Science, edited by S. M. Shapiro, S. C. Moss and J. D. Jorgensen, Mater. Res. Soc. Symp. Proc., Vol. 166 (Materials Research Society, Pittsburgh, 1990), p. 115.

Giebultowicz, T. M.; Klosowski, P.; Samarth, N.; Luo, H.; Rhyne, J. J.; Furdyna, J. K., "Antiferromagnetic Phase Transition in Cd ${ }_{1-x} \mathrm{Mn}_{x} \mathrm{Se}_{x}$ Epilayers," Phys. Rev. B 42, 2582 (1990).

Giebultowicz, T. M.; Rhyne, J. J.; Furdyna, J. K.; Klosowski, P., "Inelastic Neutron Scattering Studies of II-VI Diluted Magnetic Semiconductors," J. Appl. Phys. 67, 5096 (1990).

Glinka, C. J.; Sander, L. C.; Wise, S. A.; Berk, N. F., "Characterization of Chemically Modified Pore Surfaces by Small Angle Neutron Scattering" in Neutron Scattering for Materials Science, edited by S. M. Shapiro, S. C. Moss, J. D. Jorgensen, Mater. Res. Soc. Symp., Vol. 166 (Materials Research Society, Pittsburgh, 1990), p. 415.

Hammouda, B.; Schupp G.; Maglic, S., "QEGS from Polydimethylsiloxane in Benzene Solutions," J. Chem. Phys. (in press).

Hammouda, B., "Treatment of Asymmetric SANS Data," J. Polym. Sci., Polym. Phys. Ed. B 27,1971 (1989).

Hammouda, B.; Yelon, W. B.; Lind, A. C.; Hansen, F., "SANS from a BPAC/DMS Block Copolymer Under Uniaxial External Stretch," Macromol. 22, 418 (1989).

Hempelmann, R.; Richter, D.; Rush, J. J.; Rowe, J. M., "Hydrogen Site Distribution in the Alloy System $\mathrm{Nb}_{100 x} \mathrm{~V}_{x} \mathrm{H}_{y}$ Studied by Means of Neutron Vibrational Spectroscopy," J. Less-Common Met. (in press).

Himes, V. L.; Mighell, A. D.; Stalick, J. K.; Young, S. L.; Carr, M. J.; Lyman, C. E.; Anderson, R.; Holomany, M. A.; Jenkins, R., Elemental and Interplanar Spacing Index for Phase Identification by Electron or X-ray Diffraction, (U.S. Dept. of Commerce, NIST and the International Centre for Diffraction Data, 1989), 880 pages.

Kamitakahara, W. A., "Low Frequency Vibrational Spectra of Amorphous Solids," in Phonons 89 , edited by S. Hunklinger, W. Ludwig and G. Weiss, (World Scientific, New Jersey, 1990), p. 387.

Kamitakahara, W. A.; Biswas, R.; Bouchard, A. M.; Gompf, F.; Suck, J. B., "Vibrational Spectra for Hydrogenated Amorphous Semiconductors" in Neutron Scattering for Material Science, edited by S. M. Shapiro, S. C. Moss, J. D. Jorgensen, Mater. Res. Soc. Symp. Proc., Vol 166 (Materials Research Society, Pittsburgh, 1990), p. 361.

Kirchheim, R.; Kieninger, W.; Huang, X.Y.; Filipek, S. M.; Rush, J. J.; Udovic, T. J., "Hydrogen in Amorphous Ni-Zr and Ni-Ti Alloys," J. Less- Common Met. (in press).

Krueger, S.; Chen, S.-H.; Hofrichter, J.; Nossal R., "Small Angle Neutron Scattering Studies of HbA in Concentrated Solutions," Biophys. J. (in press).

Krueger, S.; J. W. Lynn; Russell, J. T.; Nossal, R., "Small-Angle Neutron Scattering Method for In Situ Studies of the Dense Cores of Biological Cells and Vesicles: Application to Isolated Neurosecretory Vesicles," J. Appl. Crystallogr. 22, 546 (1989). 
Krueger, S.; Long, G. G.; Page, R. A., "Multiple Small Angle Neutron Scattering Characterization of the Densification of Alumina," in Neutron Scattering for Materials Science edited by S. M. Shapiro, S. C. Moss, J. D. Jorgensen, Mater. Res. Soc. Symp. Proc., Vol. 166 (Materials Research Society, Pittsburgh, 1990), p. 61.

Krueger, S.; Olson, G. J.; Rhyne, J. J.; Blakemore, R. P.; Gorby, Y. A.; Blakemore, N., "Small Angle Neutron and X-ray Scattering from Magnetite Crystals in Magnetoactic Bacteria," J. Magn. Magn. Mater. $\underline{82}, 17$ (1989).

Krueger, S.; Olson, G. J.; Rhyne, J. J.; Blakemore, R. P.; Gorby, Y. A.; Blakemore, N., "Small Angle Neutron Scattering from Bacterial Magnetite," J. Appl. Phys. 67, 4475 (1990).

Krueger, S.; Zaccai, G.; Wlodawer, A.; Langowski, J.; O’Dea, M. Maxwell, A. and Gellert, M., "Neutron and Light-Scattering Studies of DNA Gyrase and its Complex with DNA," J. Mol. Biol. 211, 211 (1990).

Lewicki, A.; Schindler, A. I.; Furdyna, J. K.; Giebultowicz, T. M., "Magnetic Properties of Co-based Diluted Magnetic Semiconductors," in Diluted Magnetic Semiconductors, edited by M. Jain, World Scientific (in press).

Li, W-H; Lynn J. W.; Skanthakumar, S.; Clinton, T. W.; Kebede, A.; Jee, C.- S.; Crow, J. E.; Mihalisin, T., "Magnetic Order of $\operatorname{Pr}$ in $\mathrm{PrBa}_{2} \mathrm{Cu}_{3}{ }_{7}$," Phys. Rev. B 40, 5300 (1989).

Li, W-H.; Lynn, J. W.; Stanley, H. B., Udovic, T. J., Shelton, R. N.; Klavins, P., "Crystal Field Splittings in the Cubic Magnetic Superconductors $\mathrm{HoPd}_{2} \mathrm{Sn}$ and $\mathrm{ErPd}_{2} \mathrm{Sn}$," Phys. Rev. B $\underline{39}, 4119$ (1989).

Li, W-H; Lynn, J. W.; Fish, Z., "Magnetic Order of the $\mathrm{Cu}$ Planes and Chains in $\mathrm{NdBa}_{2} \mathrm{Cu}_{3} \mathrm{O}_{6+x}$," Phys. Rev. B 1ㅏ, 4098 (1990).

Lin, M.; Sinha, S. K.; Huang, J. S.; Abeles, B.; Johnson, J. K.; Drake, J. M.; Glinka, C. J., "A SANS Study of Capillary Condensation in Porous Media," in Neutron Scattering for Materials Science, edited S. M. Shapiro, S. C. Moss, J. D. Jorgensen, Mater. Res. Soc. Symp. Proc., Vol. 166 (Materials Research Society, Pittsburgh, 1990), p. 449.

Lindemuth, P.; Hammouda, B.; Duck, J. R.; Blum, F.; Venable, R., "PGSE-NMR and SANS from TPB Based Microemulsions," in Macromolecular Liquids, edited by C. R. Safinya, S. Safran, P. A. Pincus, Mater. Res. Soc. Symp. Proc., Vol 177 (Materials Research Society, Pittsburgh, 1990), p. 117.

Lindemuth, P.; Hammouda, B.: Venable, R., "SANS from TPB based Microemulsions," J. Phys. Chem. (in press).

Long, G. G.; Krueger, S., "Multiple Small Angle Neutron Scattering Characterization of the Densification of Ceramics: Application to Microporous Silica," J. Appl. Crystallogr. 22, 539 (1989).

Long, G. G.; Krueger, S.; Black, D. R.; Cline, J. P.; Jemian, P. R. Gerhardt, R. A., "Small Angle Neutron Scattering and Small Angle X-ray Scattering from Bulk Microporous Silica," in Neutron Scattering for Materials Science, edited S. M. Shapiro, S. C. Moss, J. D. Jorgensen, Mater. Res. Soc. Symp. Proc., Vol. 166 (Materials Research Society Pittsburgh, 1990 p. 421. 
Long, G. G.; Krueger, S., Jemian, P. R.; Black, D. R.; Burdette, H. E.;Cline, J. P.; Gerhardt, R. A., "Small Angle Scattering Determination of the Microstructure of Porous Silica Precursor Bodies," J. Appl. Crystallogr. (in press).

Lynn, J. W., "Magnetic Order and Spin Fluctuations in Oxide Superconductors," Physica B 163,69 (1990).

Lynn, J. W.; Clinton, T. W.; Li, W.-H.; Erwin, R. W.; Liu, J. Z.; Vandervoort, D.; Shelton, R. N., "2D and 3D Magnetic Behavior of $\mathrm{Er}$ in $\mathrm{ErBa}_{2} \mathrm{Cu}_{3} \mathrm{O}_{7}, "$ Phys. Rev. Lett. 63, 2606 (1990).

Lynn, J. W.; Clinton, T. W.; Li, W-H.; Erwin, R. W.; Liu, J. Z.; Shelton, R. N.; Klavins, P., "TwoDimensional Magnetic Order of Er in $\mathrm{ErBa}_{2} \mathrm{Cu}_{3} \mathrm{O}_{7}$," J. Appl. Phys. 67, 4533 (1990).

Lynn, J. W.; Li, W-H.; Trevino, S. F.; Fish, Z., "Pressure Dependence of the Cu Magnetic Order in $\mathrm{RBa}_{2} \mathrm{Cu}_{3} \mathrm{O}_{6+x}, "$ Phys. Rev. B 40,5172 (1989).

Lynn, J. W.; Sumarlin, I. W.; Skanthakumar, S.; Li, W-H.; Shelton, R. N.; Peng, J. L.; Fisk, Z.; Cheong, S-W., "Magnetic Ordering of $\mathrm{Nd}$ in $(\mathrm{Nd}, \mathrm{Ce})_{2} \mathrm{CuO}_{4}$, " Phys. Rev. B $\underline{41}, 2569$ (1990).

Majkrzak, C. F.; Kwo, J.; Hong, M.; Yafet, Y.; Gibbs, Doon; Chien, C. L.; Bohr, J., "Magnetic Rare Earth Superlattices,". Adv. Phys. (in press).

Majkrzak, C. F.; Felcher, G. P., "Neutron Scattering Studies of Surfacrs and Interfaces," MRS Bulletin (in press).

Majkrzak, C. F.; Satija, S.; Neumann, D. A.; Rush, J. J.; Lashmore, D.; Johnson, C.; Bradshaw, J; Passell, L.; Dinardo, R., "Determination of Hydrogen Density Profiles in Thin Films and Multilayers by Neutron Reflection," in Neutron Scattering for Materials Science, edited by S. M. Shapiro, S. C. Moss, J. D. Jorgensen, Mater. Res. Soc. Symp., vol. 166, (Materials Research Society, Pittsburgh, 1990), p. 127.

Mangin, P.; Boumazouza, D.; George, B.; Rhyne, J. J.; Erwin, R. W., "Static and Dynamic Properties of the $\left(\mathrm{Fe}_{x} \mathrm{Cr}_{1-x}\right)_{75} \mathrm{P}_{15} \mathrm{C}_{10}$ Reentrant Spin Glass Amorphous Alloy," Phys. Rev. B $\underline{40}, 11123$ (1989).

Marezio, M.; Santoro, A.; Capponi, J. J.; Hewat, E. A.; Cava, R. J.; Beech, F., "Crystal Structure, Atomic Ordering and Charge Localization in $\mathrm{Pb}_{2} \mathrm{Sr}_{2} \mathrm{YCu}_{3} \mathrm{O}_{8+Z}(\mathrm{M}=1.47)$," Physica $\mathrm{C} \underline{169}, 401$ (1990).

McKinnon, W. R.; Tselepis, E.; LaPage, Y.; McAlister, S. P.; Pleziter, C.; Tarascon, J. M.; Miceli, P. F.; Ramesh, R.; Hull, G. W.; Waszczak, J. V.; Rhyne, J. J.; Neumann, D. A., "Structure and Magnetism of $\mathrm{Bi}_{2}(\mathrm{Sr}, \mathrm{Ca})_{2} \mathrm{Mn0}_{6+y}, "$ Phys. Rev. B $\underline{41}, 4489$ (1990).

Miceli, P. F.; Tarascon, J. M.; Bagley, B. G.; Greene L. H.; Barboux, P.; Hull, G. W.; Giroud, M.; Rhyne, J. J.; Neumann, D. A., "Magnetic Properties of Some High $\mathrm{T}_{c}$ Superconducting Compounds," in High Temperature Superconductors, edited by T. Akachi, J. A. Cogordan, and A. A. Valladares, Prog. in High Temp. Superconductivity, Vol. 20, (World Scientific Publishing, Singapore, 1989), p. 89.

Miceli, P. F.; Tarascon, J. M.; Greene, L. H.; Rhyne, J. J.; Neumann, D. A. "Magnetic Ordering In $\mathrm{YBa}_{2} \mathrm{Cu}_{3-x} \mathrm{M}_{x} 0_{6+y}, "$ Physica C $\underline{162}, 1267$ (1989). 
Mighell, A. D.; Himes, V. L., "A New Method for Phase Identification for Electron Microscopists," J. Electron Microscopy Technique. 16, 155 (1990).

Moon, R.M.; Fernandez-Baca, J.A.; Hewat A.; Jorgensen, J.D.; Kamitakahara, W.; Powell, B.M.; Yelon, W.B., "Powder/Liquids Diffraction, " in Proceedings of the Oak Ridge National Laboratory/ Brookhaven National Laboratory Workshop on Neutron Scattering Instrumentation at High-Flux Reactors, Report CONF-8906311, (1990), p. 31-37.

Mozer, B.; Bendersky, L. A.; Boettinger, W. J.; Rowe, R. G.; "Neutron Powder Diffraction Study of the Orthorhombic $\mathrm{Ti}_{2} \mathrm{AlNb}$ Phase," Scripta Metallurgia (in press).

Neumann, D. A.; Nicol, J. M.; Rush, J. J.; Wada, N.; Fan, Y.; Kim, H.; Solin, S. A.; Pinnavaia, T. J.; Trevino, S. F., "Neutron Scattering Study of Layered Silicates Pillared with Alkylammonium Ions" in Neutron Scattering for Materials Science, edited by S. M. Shapiro, S. C. Moss, J. D. Jorgensen, Mater. Res. Soc. Symp. Proc., Vol. 166 (Matls. Res. Soc., Pittsburgh, 1990), p. 397.

Neumeier, J . J.; Bjornholm, T.; Maple, M. B.; Rhyne, J. J.; Gotaas, J. A., "Neutron Diffraction Study of Pr Valence and Oxygen Ordering in the $\mathrm{Y}_{1-x} \mathrm{Pr}_{x} \mathrm{Ba}_{2} \mathrm{Cu}_{3} \mathrm{O}_{7-d}$ System," Physica $\mathrm{C} \underline{166}, 191$ (1990).

Nicol, J. M.; Udovic, T. J.; Rush, J. J.; Cox, S. D.; Stuckey, G. D., "Inelastic Neutron Scattering Studies of Nonlinear Optical Materials: p- Nitroaniline Adsorbed in ALPO-5," in Neutron Scattering for Materials Science, edited by S. M. Shapiro, S. C. Moss, J. D. Jorgensen, Mater. Res. Soc. Symp. Proc., Vol. 166 (Materials Research Society, Pittsburgh, 1990), p. 367.

O'Connor, C. L., editor, "NIST Reactor: Summary of Activities July 1988 Through June 1989," NIST (U.S.) Tech. Note 1272, Dec. 1989.

Passell, L.; Carpenter, J. M.; Copley, J. R. D.; Dorner, B.; Ito, Y., "Time- of-flight," in Proceedings of the Oak Ridge National Laboratory/Brookhaven National Laboratory Workshop on Neutron Scattering Instrumentation at High- Flux Reactors, Report CONF-8906311, (1990), p. 15-23.

Parise, J. B.; Torardi, C. C.; Subramanian, M. A.; Gopalakrishnan, J.; Sleight, A. W.; Prince, E., "Superconducting $\mathrm{Tl}_{2.0} \mathrm{Ba}_{2.0} \mathrm{CuO}_{6+d}$ : A High Resolution Neutron Powder and Single Crystal XRay Diffraction Investigation," Physics C 159 , 239 (1989).

Prask, H. J. "The Reactor and Cold Neutron Facility at NIST," Neutron News 1 (1), 9 (1990).

Prask, H.; Choi, C. S., "Residual Stress Measurements by Means of Neutron Diffraction" in Neutron Scattering for Materials Science, edited by S. M. Shapiro, S. C. Moss, J. D. Jorgensen, Mater. Res. Soc. Symp. Proc., Vol. 166 (Materials Research Society, Pittsburgh, 1990), p. 293.

Prince, E., "Mathematical Aspects of Rietveld Refinement," Proceedings of the International Workshop on the Rietveld Method, Petten, The Netherland, Oxford University Press (in press).

Prince, E., "Principles of Rietveld Refinement," Proceedings of the International Workshop on the Rietveld Method, Petten, The Netherlands, Oxford University Press (in press).

Prince, E.; Evans, H. T., "The Crystal Structure of Ammonium Paradodecatunstat Tetrahydte by Neutron Diffraction," Acta Crystallogr. C ( in press).

Prince, E.; Sjölin, L., "Maximum Entropy as a Phasing Tool in Macromolecular Crystallography," Chemometrics and Intelligent Laboratory Systems (in press). 
Rhyne, J. J.; Erwin, R. W.; Borchers, J.; Salamon, M. B.; Du, R.; Flynn, C. P. "Magentic Multilayers," Phys. Scr. T29, 31, (1989).

Rhyne, J. J.; Majkrzak, C. F., "The NIST Cold Neutron Research Facility and Magnetic Neutron Scattering," J. Appl. Phys. 67, 5693 (1990).

Rowe, J. M.; Rorer, D. C., "Existing Cold Sources At U. S. Reactors". Proceedings of International Workshop on Cold Neutron Research Sources (in press).

Rush, J. J.; Flanagan, T. B.; Craft, A. P.; Clewley, J. D.; Sakamoto, Y., "The Optic Mode Frequencies and Solubilities of Hydrogen in Ordered and Disordered $\mathrm{Pd}_{3} \mathrm{Mn}, " \mathrm{~J}$. Phys.: Condens. Matter 1, 5095 (1989).

Russell, T.P.; Anastasiadis, S. H.; Satija, S. K.; Majkrzak, C. F., "Temperature Dependence of the Morphology of Thin Diblock Copolymer Films as Revealed by Neutron Reflectivity," in Neutron Scattering for Materials Science, edited by S. M. Shapiro, S. C. Moss, and J. D. Jorgensen, Mater. Res. Soc. Symp. Proc., Vol. 166 (Materials Research Society, Pittsburgh, 1990), p. 145.

Salamon, M. B.; Borchers, J.; Du, R.; Flynn, C. P.; Tsui, F.; Beach, R. S.; Erwin, R. W.; Rhyne, J. J., "Magnetic Properties of Epitaxial Metallic Superlattice," Phy. Scr. (in press).

Santoro, A. "Crystal Chemistry of Superconductors and Related Compounds," in Chemistry of Superconducting Materials, edited by T. A. Vanderah, Noyes publications (in press).

Santoro, A., "Models for Oxygen Ordering and Diffusion in $\mathrm{Ba}_{2} \mathrm{YCu}_{3} \mathrm{O}_{x}$ and $\mathrm{Ba}_{2} \mathrm{YCu}_{3-x} \mathrm{M}_{x} \mathrm{O}_{y}[\mathrm{M}=\mathrm{Fe}$, $\mathrm{Co}, \mathrm{Al}, \mathrm{Ga}$," Proc. 7th CIMTEC Meeting on Superconductors (in press).

Santoro, A., "Defective Structures of $\mathrm{Ba}_{2} \mathrm{YCu}_{3} \mathrm{O}_{x}$ and $\mathrm{Ba}_{2} \mathrm{YCu}_{3-y} \mathrm{M}_{y} \mathrm{O}_{z},(\mathrm{M}=\mathrm{Fe}, \mathrm{Co}, \mathrm{Al}, \mathrm{Ga}, \ldots), "$ in Chemistry of Superconducting Materials, edited by T. A. Vanderah, Noyes publications (in press).

Santoro, A.; Beech, F.; Cava, R. J., "Neutron Powder Diffraction Study of the Structures of $\mathrm{La}_{1.9} \mathrm{Ca}_{1.1} \mathrm{Cu}_{2} \mathrm{O}_{6}$ and $\mathrm{La}_{1.9} \mathrm{Sr}_{1.1} \mathrm{Cu}_{2} \mathrm{O}_{6+w}, "$ in Neutron Scattering for Materials Science, edited by S. M. Shapiro, S. C. Moss, J. D. Jorgensen, Mater. Res. Soc. Symp. Proc., Vol. 166 (Materials Research Society, Pittsburgh, 1990), p. 187.

Santoro, A., "Crystallography" in High Temperature Superconductivity, edited by J. W. Lynn, (Springer-Verlag, New York, 1990), p. 84.

Satija, S. K.; Majkrzak, C. F.; Anastasiadis, S. H.; Russell, T. P., "The Morphology of Symmetric Dieblock Copolymers as Revealed by Neutron Reflectivity" in Neutron Scattering for Materials Science, edited by S. M. Shapiro, S. C. Moss and J.D. Jorgensen, Mater. Res. Soc. Symp. Proc., Vol. 166 (Materials Research Society, Pittsburgh, 1990), p. 139.

Satija, S. K.; Majkrzak, C. F.; Russell, T. P.; Sinha, S. K.; Sirota, E. B.; Hughes, C. J., "Neutron Reflectivity Study of Block Copolymers Adsorbed from Solution," Macromolecules 23, 3860 (1990).

Schupp, G.; Hammouda, B.; Hsueh, C. M., "QEGS from entadecane," Phys. Rev. A 41 , 5610 (1990).

Sjölin, L.; Svensson, L.; Prince, E.; Sundell, S., "Phase Inprovement in the Structure Interpretation of Fragment $\mathrm{TR}_{2} \mathrm{C}$ from Bull Testis Calmodulin Using Combined Entropy Maximization and Solvent Flattening," Acta Crystallogr. B $\underline{46}, 209$ (1990). 
Sjölin, L.; Prince, E., "The Structure of the Backbone of a Protein from X-ray Diffraction Data from the Native Form," Science (in press).

Sjölin, L.; Prince, E.; Svensson, L. A.; Gilliland, G. L., "Maximum Entropy Phase Determination for X-ray Diffraction Data from Crystals of Native Proteins," Science (in press).

Skanthakumar, S.; Li, W-H; Lynn, J. W.; Kebede, A.; Crow, J. E.; Mihalisin T., "Magnetic Properties of $\operatorname{Pr}$ in $\mathrm{PrBa}_{2} \mathrm{Cu}_{3} \mathrm{O}_{7}$," Physica B $\underline{163}, 239$ (1990).

Skanthankumar, S; Lynn, J. W., "On the Nature of the Magentic Order and Structure of $\mathrm{Nd}_{2} \mathrm{CuO}_{4}$," Physica $\mathrm{C}$ (to be published).

Skanthakumar, S.; Zhang, H.; Clinton, T. W.; Li, W-H.; Lynn, J. W.; Fisk, Z.; Cheong, S-W., "Magnetic Phase Transitions and Structural Distortion in $\mathrm{Nd}_{2} \mathrm{CuO}_{4}$," Physica C $\underline{160}, 124$ (1989).

Skanthakumar, S.; Zhang, H.; Clinton, T. W.; Sumarlin, I. W.; Li, W-H.; Lynn, J. W.; Fisk, Z.; Cheong, S-W., "Magnetic Phase Transitions in $\mathrm{Nd}_{2} \mathrm{CuO}_{4}$," J. Appl. Phys. 674530 (1990).

Slade, R. C. T.; Ramanan, A.; West, B. C.; Prince, E., "The Structure of $\mathrm{V}_{9} \mathrm{Mo}_{6} \mathrm{O}_{40}$ Determined by Powder Neutron Diffraction," J. of Solid State Chem. 82, 65 (1989).

Stalick, J. K.; Wong-Ng, W., "Neutron Diffraction Study of the "Brown Phase" $\mathrm{BaNd}_{2} \mathrm{CuO}_{5}$," Mater. Lett. 9, 401 (1990).

Straty, G. C.; Hanley, H. J. M.; Glinka, C. J., "Shearing Apparatus for Neutron Scattering Studies on Fluids: Preliminary Results for Colloidal Suspensions," J. Stat. Phys. (in press).

Trevino, S. F., "Inelastic Neutron Scattering in Molecular Crystals" in Phonons 89, edited by S. Hunklinger, W. Ludwig and G. Weiss, (World Scientific, New Jersey, 1990), p. 7.

Tsai, D. H.; Trevino, S. F., "Investigation of Energy Transport in the Detonation Wave and Energy Sharing in Rapid Chemical Reactions," in Chemistry and Physics of Energetic Materials, edited by Surya N. Bulusu, Mathematica and Physical Sciences, Vol. 309 (1989), p. 228.

Udovic, T. J.; Rush, J. J.; Anderson, I. S.; Barnes, R. G., "Hydrogen Vibrational Modes and Anisotropic Potential in $\alpha-\mathrm{ScH}_{x}, "$ Phys. Rev. B $\underline{41}, 3460$ (1990).

Vergnat, M.: Houssaini, S.; DuFour, C.; Brunson, A.; Marchal, G.; Mangin, Ph.; Erwin, R. W.; Rhyne, J. J.; Vettier, C., "Evidence of Hydrogen Modulation in Si/Si:H Amorphous Multilayers," Phys. Rev. B 40, 1418 (1989).

Vergnat, M.; DuFour, C.; Brunson, A.; Houssaini, S.; Marchal, G.; Mangin, P.; Rhyne, J. J.; Erwin, R. W.; Vettier, C., "Multilayers and Low Angle Neutron Scattering," J. Phys. (Paris) 느, C7-202 (1989).

Wada, N.; Kamitakahara, W. A., "Inelastic Neutron and Raman Scattering Studies of Muscovite and Vermiculite Layered Silicates," Phys. Rev. B (in press).

Werner, S. A.; Overhauser, A. W.; Giebultowicz, T. M., "Neutron Diffraction Structure in Potassium near the [011] and [022] Bragg Points," Phys. Rev. B $\underline{41}, 12535$ (1990) 
Yang, K. N.; Ferreira, J. M.; Lee, B. W.; Maple, M. B.; Li, W-H.; Lynn, J. W.; Erwin, R. W., "Antiferromagnetic Ordering in Superconducting and Oxygen- Deficient Non-Superconducting $\mathrm{RBa}_{2} \mathrm{Cu}_{3} \mathrm{O}_{7-d}$ Compounds ( $\mathrm{R}=\mathrm{Nd}$ and Sm)," Phys. Rev. B $\underline{40}, 10963$ (1989).

Yethiraj, M.; Robinson, R. A.; Rhyne, J. J.; Gotaas, J. A.; Buschow, K. H. J., "Magnetic and Crystallographic Properties of UNiSn," J. Magn. Magn. Mater. 79, 355 (1989).

Yoo, J. N.; Sperling, L. H.; Glinka, C. J.; Klein A., "Characterization of Film Formation from Polystyrene Latex Particles Via SANS," Macromolecules 233, 3962 (1990).

Yu, S. C.; Lynn, J. W., "X-Ray Diffraction Studies of Ni-Cr-Based Amorphous Alloys," Jpn. J. Appl. Phys. 29, 902 (1990).

Zabel, H.; Magerl, A.; Rush, J. J.; Misenheimer, M. E., "Diffusion and Melting in Two Dimensions: A Quasi-Elastic Neutron Scattering Study of Alkali--Metals in Graphite," Phys. Rev. B 40, 7616 (1989).

Zhang, H.; Lynn, J. W.; Li, W-Hi; Clinton, T. W.; Morris, D. E., two- and Three-Dimensional Magnetic Order of the Rare-Earth Ions in $\mathrm{RBa}_{2} \mathrm{Cu}_{4} \mathrm{O}_{8}$," Phys. Rev. B 41, 11229 (1990). 
Technical and Professional Committee Participation and Leadership

American Crystallographic Association

A.I.P. Crystal Data Committee, A.D. Mighell, ACA Representative

American National Standards Institute

N-17: Research Reactors, Reactor Physics, and Shielding

T.M. Raby, Chairman, J. Torrence, alternate member.

American Nuclear Society

Standards Steering Committee, T.M. Raby, Member

Standards Subcommittee, ANS-15, Operations of Research Reactors,

T.M. Raby, Member

Working Groups ANS-15.1, ANS-15.11,

T.M. Raby, Chairman, J.F. Torrence, Member

Basic Energy Sciences Advisory Committee (DOE) (appointed by the Secretary of Energy), User Facilities Subcommittee

J.M. Rowe, Member and Subcommittee Chairman.

BNL Neutron Scattering Facility Scheduling Committee, J.J. Rush, Member

French National Center for Scientific Research (C.N.R.S.), Louis Neél Laboratory, Scientific Advisory Panel,

J.J. Rhyne, Member

Intense Pulsed Neutron Source (Argonne) and Los Alamos Neutron Scattering Center, Program Review Committees,

J.J. Rhyne, Member

International Conference on Surface X-ray and Neutron Scattering, Germany, 1991

International Advisory Committee, C.F. Majkrzak, Member

International Collaboration on Advanced Neutron Sources

Advisory Committee, J.M. Rowe, Member

International Meeting on Hydrogen in Metals, Banff, Canada, September, 1990.

Advisory Committee, J.J. Rush, Member

International Centre for Diffraction Data

Data Base Subcommittee, J.K. Stalick, Member 
International Union of Crystallography

-Commission on Crystallographic Nomenclature, Subcommittee on Statistical Descriptions in Crystallography, E. Prince, Member

-Commission on Journals, E. Prince, Member

JCPDS -- International Centre for Diffraction Data

-Crystal Data Management Board, L.D. Mighell, Member

-Crystal Data Task Group, A.D. Mighell, Member

-Database Subcommittee, A.D. Mighell, Member

-Phase Identification by Electron Diffraction Subcommittee, A.D. Mighell Member

Journal of Applied Crystallography

E. Prince, Co-Editor

Journal of Applied Physics, Editorial Board

J.J. Rhyne, Member

Los Alamos Neutron Scattering Center

Scientific Advisory Committee, J.M. Rowe, Chairman

National Organization for Test, Research and Training Reactors

T.M. Raby, Member of Executive Committee and Past Chairman

J.F. Torrence, Member and past Co-Chairman.

National Steering Committee for the Advanced Neutron Source

J.J. Rush, Chairman

Program Advisory Committee for the High Flux Beam Reactor at Brookhaven National Laboratory

C.F. Majkrzak, Member 


\section{Industrial and Academic Interactions}

As a national center for the development and application of neutron methods in condensed matter and materials science, chemical analysis and radiation standards, the Reactor Radiation Division and other NIST organizations have direct interactions and cooperative programs with 53 universities, 27 industrial and 34 foreign laboratories. Some examples of the many interactions of the Neutron Scattering Group are:

- An agreement is in place between NIST and Exxon Research and Development Corporation to jointly develop and operate a world-class small angle neutron scattering spectrometer at the NIST cold neutron source. This facility is being assembled in the guide hall for operation this winter. Cooperative research efforts on the existing SANS instrument includes work on wetting in microporous media and micellar systems.

Major design and construction work has been completed on a new NIST/NSF Center for High resolution Neutron Scattering at the CNRF which will offer U.S. scientists access to world-class capabilities in high resolution small angle neutron scattering studies of materials microstructure and in very high resolution spectroscopy of condensed materials using polarized neutron beams. The first instrument, the SANS, is scheduled for operation in the summer of 1991.

An intense cooperative research effort continues with several groups at AT\&T Bell Laboratories on the systematic studies of the structure and properties of new high-temperature superconductor compounds. Other superconductor research efforts involve collaborative work with Dupont, SRI and a number of universities.

A PRT agreement has been established with IBM for the development and application of neutron reflectometry for unique studies of surface and interfacial structure of polymer films, liquids and other materials. This research has thus far led to the best results worldwide in neutron studies of polymer surfaces.

The Reactor Radiation Division's Crystal Data Center is engaged in a number of interactive links including joint development and distribution to U.S. science and industry of evaluated crystal data with the International Center for Diffraction Data. The Data Center also has long-term agreements in place with crystal data programs in Canada, Great Britain, and Germany to jointly develop and share critical data on the structure of materials. An expansion of database systems into electron diffraction and microscopy has recently been achieved in cooperation with Sandia. Several instrument companies have already integrated this new data base into their products. 
The Neutron Scattering Group has in place wide collaborative research with the University of California (Santa Barbara) involving neutron inelastic scattering, neutron diffraction, and SANS studies of catalysts, non-linear optical materials, and radiation damage.

Extensive cooperative research efforts with the Physics Department and Materials Research Laboratory at the University of Illinois and with Michigan State have continued during the past year including neutron diffraction studies of magnetic multilayer materials and research on new kinds of metal-molecular complexes created within the layers of pillared clays and oriented graphite. Joint NIST/Illinois efforts have also been extended to the first use of neargrazing angle neutron diffraction in surface structure studies including magnetic diffraction on thin film.

Cooperative Research Program with the Department of Physics and Astronomy of the University of Maryland. Under this program RRD staff are engaged with Maryland scientist in joint research on magnetic materials, superconductors and catalysts. Some of this research is carried out jointly with scientists from industrial labs.

- An extensive collaborative research effort continues with Bell Communications Research focussing on magnetic substitutions and interactions in high $\mathrm{T}_{c}$ superconductors. Associated research is also underway with Johns Hopkins on the effect of atomic substitution on superconductivity.

The University of Minnesota through it's Center for Interfacial Engineering (CIE) has agreed to participate with the Reactor Radiation Division in the development and use of two high-resolution instruments at the Cold Neutron Research Facility (CNRF): a 30meter Cold Neutron Small-Angle Scattering Spectrometer and a Cold Neutron Reflectometer. The CIE, with it's thirty affiliate or sponsoring companies, will use these instruments with NIST for the elucidation of the structure and microstructure of polymers and other materials as well as surface and interfacial structure and interactions.

The Center for Materials Science and Engineering at the MIT has agreed to participate with the Reactor Radiation Division in the development and use of a new 32-detector, high resolution powder neutron diffractometer for materials research at the NIST Reactor. The new instrument will be a world-class diffractometer with state-of-the-art capabilities in resolution, versatility, and data collection efficiency. Of particular initial interest in the collaborative program are structural studies of graphite intercalation compounds and fast-ion conductors, and advanced ceramics. 
During the past year scientists in the Reactor Radiation Division delivered 40 invited lectures in the U.S. and abroad. Group members were invited participants in a number of workshops in the neutron field. Neutron Group scientists also continue to share several NATO grants with French and German colleagues in different areas of condensed matter physics. Joint research continues with ORNL and two small companies in the development of supermirrors. A senior engineer from the Institute Laue Langevin spent six months as a visitor on the Cold Neutron Project as part of the RRD/ILL cooperative agreement. 


\begin{tabular}{|c|c|c|}
\hline \multirow{3}{*}{$\begin{array}{l}\text { NIST-114A } \\
\text { (REV. 3-90) }\end{array}$} & \multirow{3}{*}{$\begin{array}{l}\text { U.S. DEPARTMENT OF COMMERCE } \\
\text { NATIONAL INSTITUTE OF STANDARDS AND TECHNOLOGY } \\
\text { BIBLIOGRAPHIC DATA SHEET }\end{array}$} & $\begin{array}{l}\text { 1. PUBLCATION OR REPORT NUMBEA } \\
\text { NISTIR } 4398\end{array}$ \\
\hline & & $\begin{array}{ll}2 & \text { PEAFORMINO ORGANIZATION REPOAT NUMBER }\end{array}$ \\
\hline & & $\begin{array}{l}\text { 3. PUBUCATION DATE } \\
\text { November } 1990\end{array}$ \\
\hline
\end{tabular}

4. TITLE AND SUBTITLE

Technical Activities 1990 - Reactor Radiation

5. AUTHOR(S)

J. J. Rush, Editor

6. PERFORMINO ORGANIZATION (IF JOINT OA OTHER THAN NIST, SEE INSTRUCTIONS)

U.S. DEPARTMENT OF COMMERCE

NATIONAL INSTITUTE OF STANDARDS AND TECHNOLOQY

GAITHERSBURG, MD 20899

7. CONTRACT/GRANT NUMBER

9. SPONSORINO ORGANIZATION MAME AND COMPLETE ADORESS (STAEET, CITY, STATE, ZIP)

10. SUPPLEMENTARY NOTES

11. ABSTRACT (A 200-WOAD OR LESS FACTUAL SUMMARY OF MOST SIGMIFICANT INFORMATION. IF DOCUMENT INCLUDES A SIGMIFICANT BIBLIOGRAPHY OR UTERATURE SURVEY, MENTION IT HERE.)

This report summarizes all those programs which depend on the NIST reactor. It covers the period from October 1, 1989 through September 30, 1990. The programs include the application of neutron methods to the characterization of materials, neutron standards, trace analysis by neutron activation analysis, neutron depth profiling, nondestructive evaluation and the production of radioisotopes.

12. KEY WORDS (6 TO 12 ENTRIES; ALPHABETICAL ORDER; CAPITALUZ ONLY PROPER NAMES; AND SEPARATE KEY WORDS BY SEMICOLONS)

activation analysis; crystal structure; diffraction; isotopes; molecualr dynamics; neutron; neutron radiography; nondestructive evaluation; nuclear reactor; radiation

FOR OFFICIAL DISTRIBUTION. DO NOT RELEASE TO NATIONAL TECHNICAL INFORMATION SERVICE (NTIS).

ORDER FROM SUPERINTENDENT OF DOCUMENTS, U.S. GOVERNMENT PRINTING OFFICE, WASHINGTON, DC 20402.

ORDER FROM NATIONAL TECHNICAL INFORMATION SERVICE (NTIS), SPRINGFIELD, VA 22161.

14. NUMBER OF PRINTED PAGES

15. PRICE 
1

I

I

1 If 

